\title{
CARACTERIZAÇÃO GEOLÓGICA E GEOFÍSICA DO SISTEMA AQUÍFERO URUCUIA E DE SEU SUBSTRATO NAS BACIAS DOS RIOS ARROJADO E FORMOSO, BAHIA
}

\author{
Olivar Antônio Lima de Limaª e Emerson Sidinei Mota dos Santos² \\ Recebido em 6 maio, 2010 / Aceito em 21 outubro, 2011 \\ Received on May 6, 2010 / Accepted on October 21, 2011
}

\begin{abstract}
The regional hydrogeological characteristics of the Urucuia aquifer system and of its substratum within the Arrojado and Formoso river basins were studied using well logs, gravimetric and geodetic data and geoelectrical soundings. Geophysical and lithologic data analysis from deep water wells, drilled in the area and also within the Cachorro and Fêmeas river basins, allow to identify three main units composing the Urucuia Group that, from top to bottom, are being referred as Serra das Araras, Posse and Geribá formations. Five hundred and sixty five gravimetric and geodetic GPS stations were measured in the area, at an approximated density of three station $/ 100 \mathrm{~km}^{2}$. Regional Bouguer and residual gravity maps were constructed and used to describe the structural conformation of the geological substratum underlying the Urucuia Group. Sixty five Schlumberger resistivity soundings, expanded to a maximum current AB/2 spacing of 1,000 m were used to define the aquifer geometry and the structure of its substratum within the depth range from 0 to $500 \mathrm{~m}$. The automatic inversion of the apparent resistivity data were constrained by the water table depth measured at some control wells. These results also allow to infer the general unconfined nature of the groundwater flow within the aquifer and to map an internal groundwater divide in the occidental portion of the basin. In some places, there is a local confinement caused by intense silicification of some sandstone horizons. The combined results essentially confirm the substratum topography and the block faulting structure inferred from the terrain morphology.
\end{abstract}

Keywords: stratigraphic analysis, geophysical well logs, geoelectrical soundings, gravity data, Urucuia aquifer.

RESUMO. As características hidrogeológicas do sistema aquífero Urucuia e de seu substrato nas bacias dos rios Arrojado e Formoso foram estudadas usando dados geológicos de poços, dados gravimétricos e geodésicos e sondagens elétricas verticais. Perfis litológicos e geofísicos de poços profundos perfurados no Grupo Urucuia nas vizinhas sub-bacias dos rios das Fêmeas e dos Cachorros, possibilitaram a identificação de três fácies geofísicas constituintes dessa sequência, identificadas como as formações geológicas denominadas de: Serra das Araras, Posse e Geribá. Quinhentas e sessenta e cinco estações gravimétricas e geodésicas foram levantadas na área com uma densidade aproximada de três estações por $100 \mathrm{~km}^{2}$. Mapas de isovalores da gravidade absoluta, de anomalias Bouguer e de anomalias gravimétricas residuais permitiram definir mais precisamente a estrutura de blocos falhados inferida a partir da morfologia do terreno, assim como delinear a configuração regional do substrato geológico subjacente ao Grupo Urucuia. Sessenta e cinco sondagens elétricas Schlumberger, expandidas até uma separação máxima de eletrodos de corrente $\mathrm{AB} / 2$ de $1.000 \mathrm{~m}$, foram usadas para definir a geometria do aquífero e a estrutura de seu substrato no intervalo de profundidades entre 0 e $500 \mathrm{~m}$. A inversão automática unidimensional dos dados de resistividade versus $\mathrm{AB} / 2$ foi calibrada com dados de poços, fixando-se os valores da profundidade do nível freático. Os resultados geoelétricos permitiram inferir a natureza não-confinada do fluxo subterrâneo no aquífero e mapear algumas de suas interfaces geológicas internas. Permitiram também definir a estrutura e composição do seu substrato, assim como detectar um divisor de fluxo hídrico subterrâneo na porção ocidental da área. Localmente, é possível a ocorrência de condições de confinamento parcial causadas por intensa silicificação de alguns horizontes arenosos.

Palavras-chave: análise estratigráfica, perfilagem geofísica de poços, sondagens geoelétricas, dados gravimétricos, aquífero Urucuia.

\footnotetext{
${ }^{1}$ Centro de Pesquisa em Geofísica e Geologia e Instituto de Geociências, UFBA, Campus Universitário de Ondina, 40170-290 Salvador, BA, Brasil - E-mail: olivar@cpgg.ufba.br

${ }^{2}$ Curso de Pós-graduação em Geofísica, UFBA, Campus Universitário de Ondina, 40170-290 Salvador, BA, Brasil - E-mails: esms@cpgg.ufba.br; emersonsidinei@yahoo.com.br
} 


\section{INTRODUÇÃo}

0 denominado Chapadão Urucuia corresponde a uma região de relevo aplainado com altitudes variando de 900-1000 m, no limite entre os estados da Bahia, Goiás e Tocantins, até 550-650 m, próximo ao rio São Francisco. Esse extenso planalto contém 0 divisor das águas superficiais entre as bacias dos rios Tocantins e São Francisco, referido como a escarpa da Serra Geral. Nele, toda a rede de drenagem constituída por rios e riachos perenes, afluentes da margem esquerda do rio São Francisco, tem padrão de cursos retilíneos e subparalelos, geralmente orientados de WSW para ENE. São rios competentes, estruturalmente controlados, que constituem a expressão superficial do fluxo hídrico em um dos maiores reservatórios de água potável do País. É esse amplo sistema hidráulico que regula uma grande parcela da vazão do rio São Francisco.

0 sistema aquífero Urucuia, no estado da Bahia, compreende uma espessa sequência de arenitos fluvio-eólicos, contendo intercalações de siltitos e folhelhos, do Grupo Urucuia, depositado no início do período Cretáceo. Constitui a morfologia de chapadão, com cerca de $80.000 \mathrm{~km}^{2}$ de extensão, esculpido em terrenos dominantemente arenosos com espessura máxima superior a $400 \mathrm{~m}$.

As bacias dos rios Arrojado e Formoso, pertencentes ao Chapadão Urucuia, no extremo ocidental do estado da Bahia, ocupam uma área de cerca de 20.000 km² (Fig. 1). Nesta região, como em todo 0 Chapadão Urucuia, nas últimas décadas, tem-se desenvolvido um processo acelerado de agricultura mecanizada, com irrigação permanente e de grande consumo de água, principalmente em culturas de soja, café, arroz e algodão. Grande número de poços foi perfurado no aquífero Urucuia, tanto para abastecimento humano quanto para extensivas irrigações. Todavia, sua hidrogeologia não está, ainda, avaliada com propriedade.

0 clima no chapadão é do tipo tropical quente e úmido, com pluviometria média anual crescendo de 700 a $1.600 \mathrm{~mm}$, do rio São Francisco para oeste. 0 período das chuvas estendese de novembro a abril, com alturas máximas mensais acima de $100 \mathrm{~mm}$, geralmente entre dezembro e fevereiro. Nos meses restantes atua um regime de estiagem prolongada. As máximas temperaturas situam-se entre 30 e $33^{\circ} \mathrm{C}$ no verão, enquanto as mínimas entre 18 e $20^{\circ} \mathrm{C}$, no inverno. A evapotranspiração potencial varia no intervalo de 1.100 a 1.200 mm/ano (Brasil, 1982).

No presente trabalho são interpretados e integrados dados litológicos e geofísicos de poços, juntamente com medições gravimétrico-geodésicas e de sondagens elétricas verticais, obtidos na área do entorno das bacias hidrográficas dos rios Arrojado e Formoso. Seu principal objetivo é o de definir, em escala regio- nal, as feições geométrico-estruturais, as características hidráulicas e a qualidade da água dos principais horizontes aquíferos do Grupo Urucuia, na região de estudo. Dados de perfilagens geofísicas de dois poços separados por mais de $100 \mathrm{~km}$ de distância e com quase $300 \mathrm{~m}$ de profundidade permitiram subdividir 0 Grupo Urucuia em três formações geológicas. Além disso, dados de quinhentas e sessenta e cinco estações gravimétricogeodésicas e de sessenta e cinco sondagens elétricas verticais de resistividade foram distribuídos na área, no intuito de definir suas características hidrogeológicas. Constitui, assim, uma contribuição técnico-científica desenvolvida para melhor entender o comportamento hidrogeológico do Grupo Urucuia e de seu substrato geológico na área selecionada para estudo (Fig. 1).

\section{CARACTERIZAÇÃO GEOLÓGICA}

0 Grupo Urucuia compõe-se de arenitos quartzosos de cores variadas, predominando castanha-avermelhada, rósea e amarelaesbranquiçada. Tais arenitos têm granulometrias variando de fina a média, são friáveis e limpos, mas, muitas vezes, contêm argilas em suas matrizes e, localmente, aparecem cimentados com material silicoso ou carbonático. Incluem intercalações siltosas e síltico-argilosas e frequentes níveis conglomeráticos dispersos. Zonas silicificadas são comuns ao longo de fraturas e falhas e ocorrem em horizontes subsuperficiais atravessados por muitos poços tubulares. Com base na flora de micro e macrofósseis, foi datado como de idade Cretáceo Inferior (Moutinho da Costa et al., 1976; Ghignone, 1979).

\section{Revisão da literatura}

A estratigrafia da sequência Urucuia não está ainda bem estabelecida, tanto no que se refere à nomenclatura quanto a sua caracterização faciológica. Oliveira (1967), trabalhando na parte sudoeste da bacia do rio São Francisco, dividiu a chamada Formação Urucuia em dois membros. 0 inferior, denominado Membro Geribá, seria representado por uma sucessão dominantemente argilosa, composta de folhelhos, siltitos, argilitos arenosos e calcíferos, de cores vermelho-tijolo, vermelho ou róseo. 0 superior, denominado Membro Abaeté, englobaria a sequência relativamente espessa e homogênea de arenitos quartzosos róseos, finos a médios, muitas vezes impuros e com níveis conglomeráticos locais. Estratificações cruzadas acanaladas e seixos facetados nos conglomerados caracterizam as estruturas internas desse membro.

Campos \& Dardenne (1997), trabalhando na parte mineira da bacia sanfranciscana, subdividiram 0 chamado Grupo Urucuia nas formações Posse e Serra das Araras. A primeira seria 


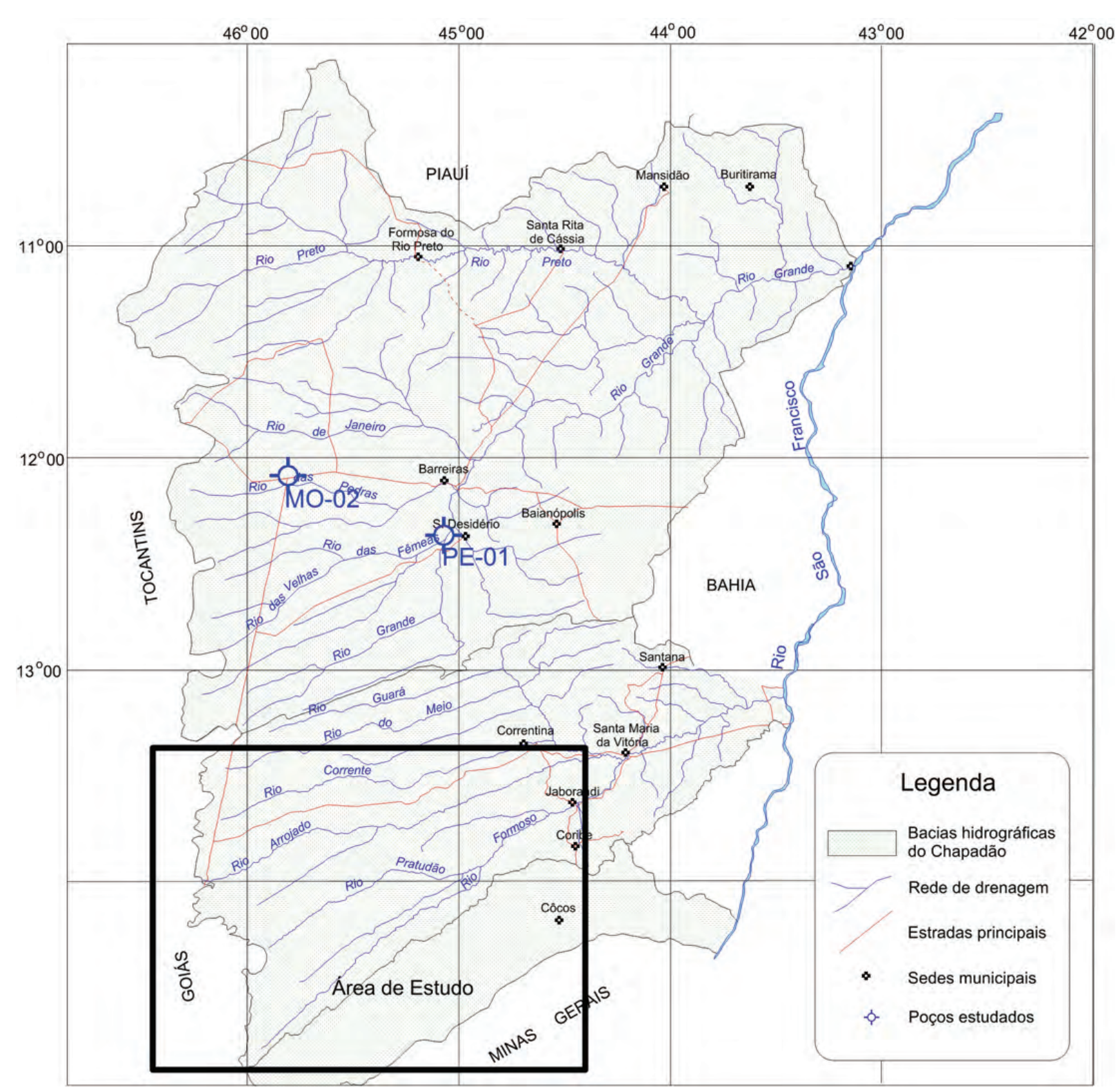

Figura 1 - Mapa de localização da área de estudo nas bacias hidrográficas que drenam o Chapadão Urucuia.

constituída de arenitos e siltitos argilosos intercalados, e a segunda compreenderia uma sequência arenosa mais grosseira, correspondendo à unidade denominada como Membro Abaeté por Oliveira (1967).

Em geral, em função de estruturas sedimentares internas e do seu conteúdo fossilífero, o Grupo Urucuia tem sido interpretado como depositado em ambiente continental, inicialmente lacustre, passando a fluvial dominante, com expressivas contribuições eólicas (Lima \& Leite, 1978; Ghignone, 1979). Essa espessa cobertura de plataforma formou-se em resposta à transgressão
Albo-aptiana que sucedeu a separação continental entre a América do Sul e a África (Ghignone, 1979).

0 Grupo Bambuí constitui o substrato sobre 0 qual foram depositados, em discordância erosiva, os depósitos do Grupo Urucuia. Compreende uma espessa sequência pelítico-carbonática, de idade Proterozoica. Compõe-se de calcários, calcários dolomíticos, dolomitos, margas, siltitos e argilitos, resultantes de uma sedimentação em mar epi-continental raso, com subsidência variável ao longo de sua extensão. Foram identificados, nessa sequência, pelo menos três episódios transgressivos, com seus 
ciclos regressivos associados (Dardenne, 1978). 0 ciclo mais superior, representado pela Formação Três Marias, compõe-se de ardósias, meta-siltitos argilosos e meta-arcóseos de cores verde e cinza-esverdeado, contendo lentes de margas e calcários.

Embora não haja registros no Brasil de atividades tectônicas expressivas após o Cretáceo, a orientação de grandes fendilhamentos no Grupo Bambuí (alinhados preferencialmente segundo N60-70E) controlou a evolução tectônica dos depósitos Urucuia (Moutinho da Costa et al., 1976). Movimentos de reativação ao longo dessas linhas de fraqueza produziram conjuntos conjugados de falhas e fraturas subverticais, que expressam-se na rede de drenagem retilínea em malha retangular (Fig. 1), que caracteriza toda a região. Algumas falhas e fraturas podem ser reconhecidas no campo pela presença de estruturas cataclásticas e intensa silicificação, que geram verdadeiras muralhas nas escarpas de vários "canyons" da região.

\section{Análise Estratigráfica do Grupo Urucuia}

Nessa subseção se propõe uma modificação na coluna estratigráfica adotada para o Grupo Urucuia no estado da Bahia, considerando os seguintes elementos: (i) os trabalhos geológicos anteriores realizados por geólogos da Petrobras, da Academia e de órgão estaduais e federais de pesquisa geológica; (ii) a constatação de haver escassez e dispersão de afloramentos, na maior parte da área do chapadão; e (iii) a disponibilidade de dados geofísicos e descrições de amostras de calha de dois poços de exploração de água subterrânea, com $280 \mathrm{~m}$ de profundidade, atravessando praticamente quase toda a sequência Urucuia.

Com base nos dados geológicos e geofísicos dos poços M0-02 e PE-01, perfurados nas sub-bacias do rio das Fêmeas e dos Cachorros, localizadas a cerca de $200 \mathrm{~km}$ ao norte da área de estudo, propõe-se a subdivisão do Grupo Urucuia em três formações, adicionando-se à classificação de Campos \& Dardenne (1997) a Formação Geribá, que possui características similares as do membro inferior da subdivisão proposta por Oliveira (1967), ora elevado à categoria de formação geológica. Seu contato com a Formação Posse é gradativo, definido por uma zona de transição com cerca de $20 \mathrm{~m}$ de espessura.

A Figura 2 mostra as colunas litológicas e os perfis geofísicos executados nos poços produtores M0-02, que abastece a cidade de Luiz Eduardo Magalhães, e PE-01, posicionado na localidade de Perdizes, município de São Desidério. Nesses poços de quase $280 \mathrm{~m}$ de profundidade foram corridos perfis elétricos [resistividades aparentes normal curto (SN) e indução (ILD), e potencial espontâneo (SP)], radioativo (radiação gama), sônico compensado e calibre do diâmetro do furo. As colunas litológicas nos centros das figuras foram definidas com base na descrição de amostras de calha fornecidas pelos perfuradores, complementadas com a análise desses dados geofísicos. Esses dois poços, que distam entre si cerca de $100 \mathrm{~km}$, mostram excelentes correlações faciológicas e atestam a validade regional da presente análise.

Integrando os dados geofísicos obtidos nos poços MO-02 e PE-01 com os parâmetros hidráulicos e petrofísicos deles computados, foi possível verificar que, efetivamente, o Grupo Urucuia, na bacia do São Francisco, é constituído por três fácies geofísicas distintas, cada uma delas constituindo uma formação geológica de características litológicas específicas, assim definidas:

(i) Fácies Superior (Formação Serra das Araras) - Presente nos dois poços está mais bem caracterizada no perfil do poço M0-02 (Fig. 2). Corresponde a uma sucessão de arenitos avermelhados, de granulação média a fina, friáveis, argilosos e estratificados em bancos de 2 a $4 \mathrm{~m}$ de espessura, nos quais, geralmente, 0 teor de argila aumenta da base para o topo do banco. É comum a presença de níveis silicificados intercalados, identificados por fortes crescimentos na resistividade ILD e por anomalias distintas nas curvas de velocidade sônica. Esta fácies apresenta uma espessura de $82 \mathrm{~m}$ no poço M0-02 e possui, no topo, uma camada guia de alta argilosidade e aproximadamente $20 \mathrm{~m}$ de espessura. Essa camada guia, de maior condutividade, foi reconhecida em quase todas as sondagens elétricas realizadas na área. Esta unidade separa-se da fácies sotoposta por meio de uma superfície erosiva definida em termos dos contrastes físicos manifestados nos perfis elétricos e sônico.

(ii) Fácies Intermediária (Formação Posse) - Identificada nos dois poços, alcança uma espessura aproximada de $130 \mathrm{~m}$. Compõe-se de arenitos rosa-acinzentados, de granulação média a fina, com proporção de argila bem menor que a da fácies superior $(<10 \%)$. Localmente, pode conter horizontes com argilosidade um pouco mais alta (15 a 30\%). Pode ser identificada pelo empilhamento de corpos arenosos com algumas dezenas de metros de espessura. A porosidade efetiva ao longo da seção varia de 8 a 22\%, enquanto a permeabilidade oscila entre menos de 100 a um pouco mais de 1,0 Darcy (Fig. 3).

(iii) Fácies Inferior (Formação Geribá) - Parcialmente penetrada pelos dois poços, tem espessura da ordem de 


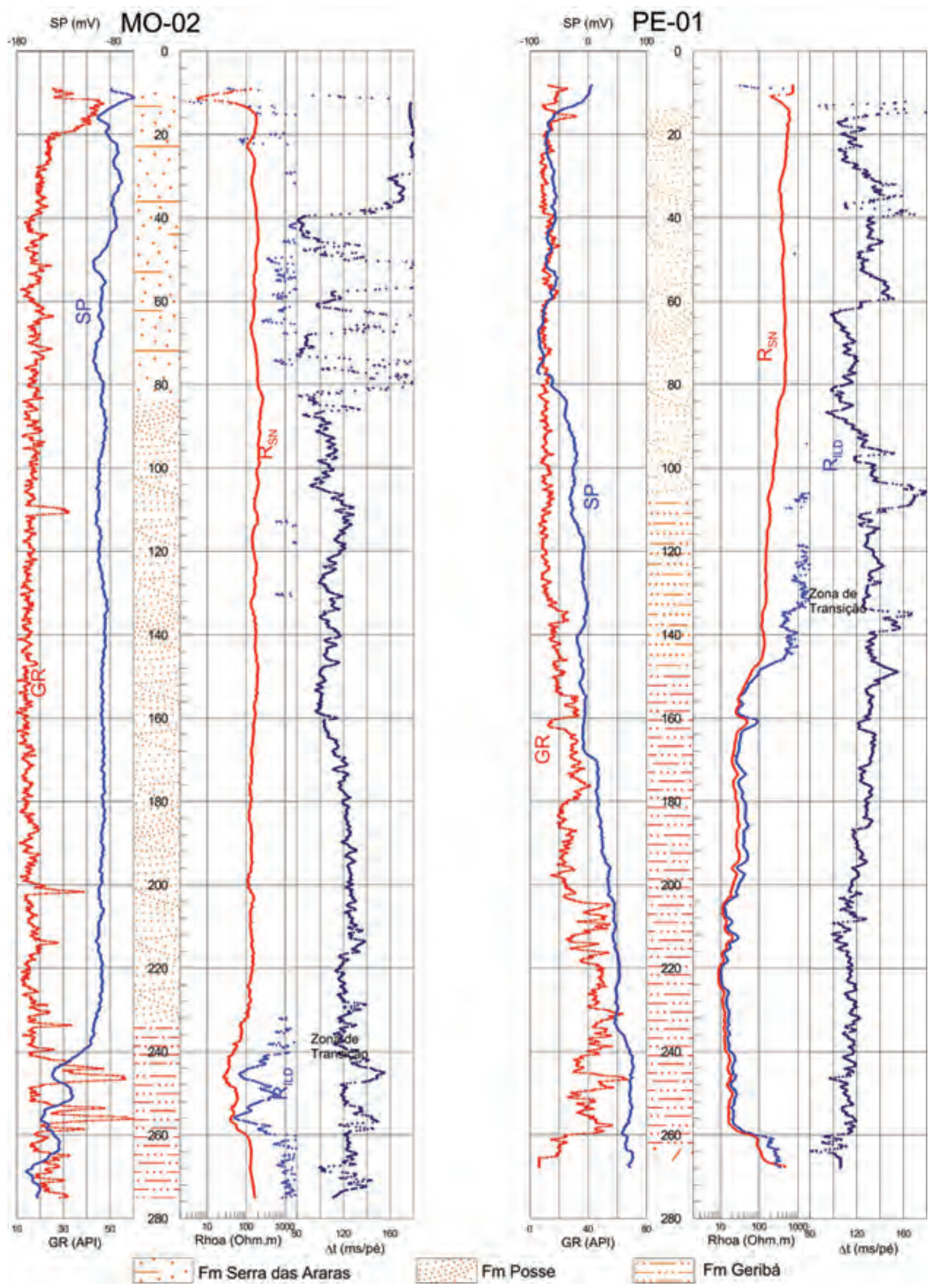

Figura 2 - Perfis geofísicos corridos nos poços M0-02 e PE-01 que abastecem a cidade de Luiz Eduardo Magalhães e a vila de Perdizes. 
110 m. Compõe-se de arenitos argilosos (15 a 30\% de argilas), de granulação fina, com intercalações delgadas de horizontes argilosos avermelhados. Estes gradam, no sentido da base da seção, para espessos argilitos ou folheIhos (com 60 a 100\% de argilas) marrom-avermelhados, contendo intercalações de arenitos finos e siltitos. $\mathrm{Na}$ base de PE-01 (Fig. 2) foi identificado um nível conglomerático de matriz areno-argilosa fina contendo seixos de quartzo, silexitos e carbonatos. Faz contato transicional com a fácies intermediária, conforme indicado pelas propriedades físicas medidas nos furos. Essa zona de transição tem cerca de $20 \mathrm{~m}$ de espessura e, através dela, tanto a porosidade quanto a permeabilidade passam por valores bem pequenos (Fig. 3).

\section{CARACTERIZAÇÃO PETROFÍSICA E GEOFÍSICA}

A condução elétrica nas rochas da parte superior da crosta terrestre é basicamente determinada pelo conteúdo e salinidade de seu eletrólito, pelo volume e conectividade de seus espaços vazios e pela proporção de minerais portadores de uma condutividade superficial dispersos na sua matriz de sólidos. Por isso, os métodos elétricos e eletromagnéticos têm sido largamente utilizados na hidrogeologia e em estudos de poluição subterrânea, com resultados altamente satisfatórios (Ward, 1990; Lima et al., 1995; Meju et al., 1999).

\section{Caracterização petrofísica}

0 perfil de radiação gama é um bom indicador da variabilidade litológica vertical ao longo de um furo. Em sucessões areno-argilosas, 0 aumento na contagem API, da radiação gama detectada, corresponde a um aumento na proporção de argila num pacote sedimentar (Asquith, 1990). 0 conteúdo de argila, ou argiIosidade de um arenito, pode ser avaliado a partir desses perfis usando uma equação empírica não-linear, conforme descrito em Asquith \& Gibson (1982). Inicialmente, calcula-se um índice de radiação gama usando a fórmula

$$
I_{G R}=\frac{G R_{\log }-G R_{\min }}{G R_{\max }-G R_{\min }},
$$

onde $G R_{\log }$ é a leitura do perfil e $G R_{\min }$ e $G R_{\max }$ são, respectivamente, as leituras mínima e máxima observadas no intervalo perfilado. A fração volumétrica de argila na matriz é calculada então da seguinte expressão:

$$
V_{c l}=0,33\left[2^{2 I_{G R}}-1,0\right] .
$$

Os dados dos perfis elétricos corridos nos poços M0-02 e
PE-01 vêm mostrados nas duas faixas à direita das colunas litológicas dos furos, representadas na Figura 2. Usando esses dados e 0 modelo de condutividade volumétrica para arenitos argilosos proposto por Lima \& Sharma (1990; 1992) e refinado por Lima \& Sri Niwas (2000) e Lima et al. (2005), foram computadas a porosidade efetiva $\left(\phi_{e}\right)$ e a permeabilidade $(k)$ dos arenitos através das relações

$$
\phi_{e}=\left(\frac{\rho_{m f}}{\rho_{x o}}\right)\left\{\frac{\rho_{c s}^{1 / m}-\rho_{x o}^{1 / m}}{\rho_{c s}^{1 / m}-\rho_{m f}^{1 / m}}\right\},
$$

e

$$
k=\alpha_{o}\left[\frac{\phi_{e}^{(m-1+1 / q)}}{1+\delta_{c} \sigma_{c s}}\right]^{q} .
$$

Nas Equações (3) e (4), $\rho_{x o}$ e $\rho_{m f}$ são, respectivamente, a resistividade elétrica da zona lavada e a do eletrólito intersticial (filtrado da lama) e $\rho_{c s}=1 / \sigma_{c s}$ é a resistividade (1/condutividade) equivalente dos sólidos de sua matriz. A grandeza $\delta_{c}$ é um parâmetro característico do tipo de argila presente na matriz de cada formação. As constantes $\alpha_{o}, m$ e $q$ são determinadas empiricamente usando dados experimentais de amostras de arenitos argilosos, de várias partes do mundo (Lima \& Sri Niwas, 2000). As Equações (3) e (4) foram usadas para computar distribuições de porosidade efetiva e de permeabilidade intrínseca dos arenitos ao longo dos dois furos. A condutividade da matriz $\left(\sigma_{c s}\right)$ foi determinada supondo uma estrutura de grãos de areia capeados por folhelhos, com proporção dada pela argilosidade calculada a partir dos perfis de radiação gama.

Os perfis sônicos compensados vêm mostrados nas segundas faixas da direita, ao lado dos perfis elétricos (Fig. 2). Eles representam 0 tempo médio de propagação $(\Delta t)$ ao longo de 1,0 pé da litologia penetrada pelo som emitido de um transmissor na sonda. Nos trechos mais regulares dos dois perfis, os dados de $\Delta t$ permitiram computar valores confiáveis de porosidade total dos arenitos usando a fórmula do tempo médio (Wyllie et al., 1956) dada por

$$
\phi=\frac{\Delta t-\Delta t_{m}}{\Delta t_{m}-\Delta t_{f}} \times \frac{1}{B_{c p}}
$$

onde $\Delta t$ é 0 tempo lido em cada ponto do perfil, $\Delta t_{m} 0$ tempo de trânsito da onda $P$ na matriz sólida da rocha $\left(\Delta t_{m}=55 \mathrm{~ms} /\right.$ pé para arenitos quartzosos), $\Delta t_{f} 0$ tempo de trânsito no fluido dos poros ( $\Delta t_{f}=189 \mathrm{~ms} /$ pé para água doce) e $B_{c p}$ é um fator de correção para a compactação do pacote. 0 valor de $B_{c p}$ é estimado do tempo de propagação observado nos horizontes argilosos da seção (Schlumberger, 1989). 

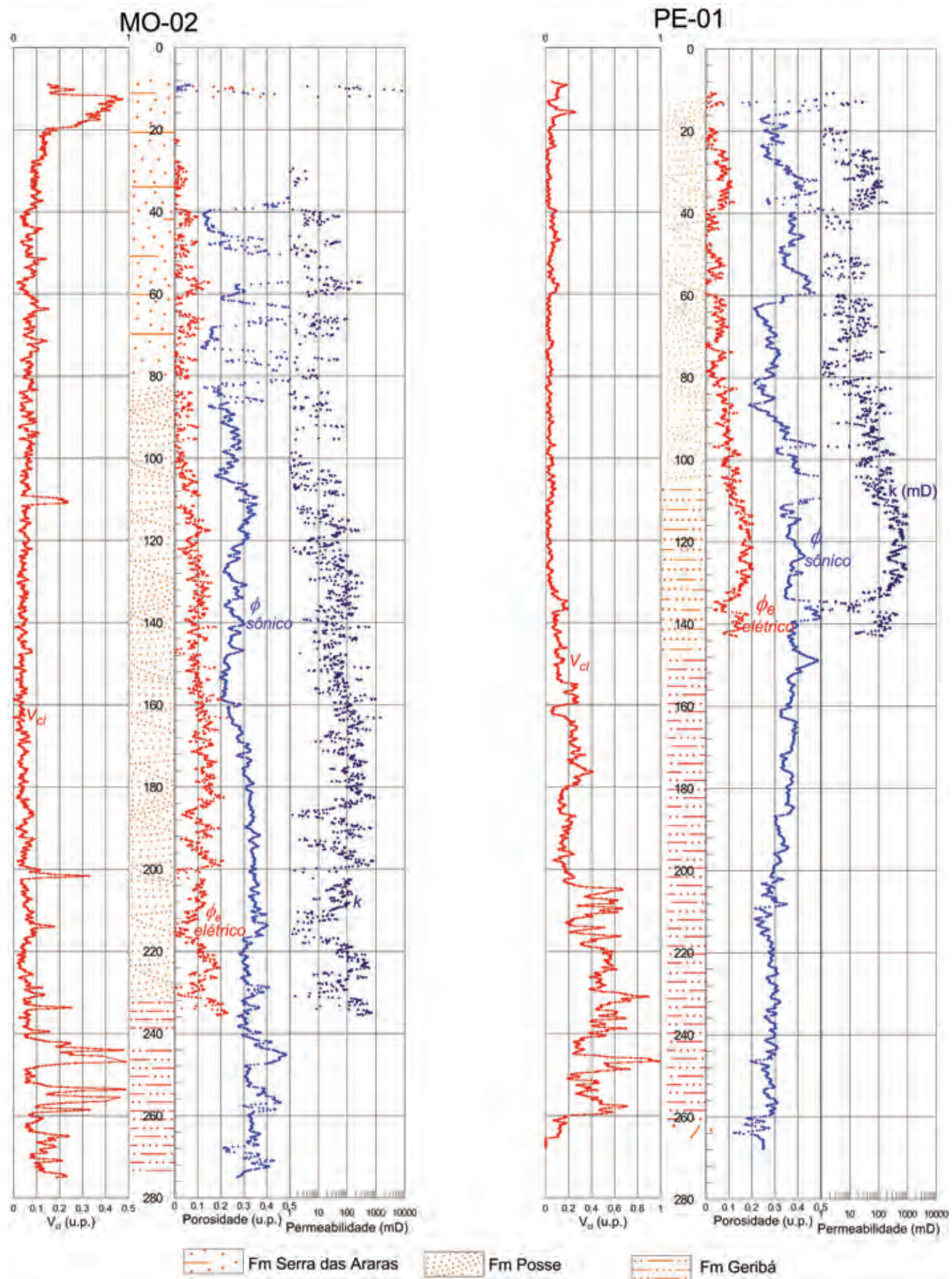

Figura 3 - Parâmetros petrofísicos dos arenitos do Grupo Urucuia estimados dos perfis geofísicos dos poços M0-02 e PE-01. 
Assim, do perfil de radiação gama foi possível demarcar horizontes contendo argilas ao longo das seções colunares dos poços M0-02 e PE-01 (Fig. 3). Além disso, foi possível constatar que os pacotes arenosos que estendem-se de 82 a $230 \mathrm{~m}$ de profundidade no poço M0-02 e de 0 a $143 \mathrm{~m}$ no poço PE-01 correspondem aos trechos mais limpos e uniformes das duas seções. 0 pacote argilo-arenoso do topo da coluna de M0-02, com $20 \mathrm{~m}$ de espessura, mostra um crescimento, da base para 0 topo, na argilosidade da formação. Esse intervalo não foi identificado no poço PE-01. Nos intervalos de profundidade entre 240 e $280 \mathrm{~m}$, em M0-02 e de 190-230 m, em PE-01, ocorrem arenitos argilosos finos e mal selecionados, intercalados com folhelhos e siltitos avermelhados. Níveis argilosos esporádicos ocorrem ao longo de todo o pacote Urucuia.

Os valores de resistividade aparente, nas primeiras faixas da direita da Figura 2 (com respeito às colunas litológicas centrais) mostram que as leituras da ferramenta IEL, de maior raio de investigação, são muito elevados, indicando que a maior parte do Grupo Urucuia é muito resistiva. Deflexões geradas por horizontes mais condutivos distribuídos entre 25 e $85 \mathrm{~m}$ de profundidade, em M0-02, e entre 30-56 m, em PE-01, parecem representar zonas alternadas de arenitos friáveis com níveis arenosos muito silicificados. Essas zonas possuem baixa argilosidade e relacionam-se às variações irregulares nas paredes do furo, conforme infere-se do comportamento dos perfis sônicos mostrados nas segundas faixas da direita na Figura 2. Os dados de SP e de resistividade SN são menos diagnósticos, em função das resistividades relativamente elevadas dos arenitos, mas, qualitativamente, apontam para a mesma variação de composição descrita.

\section{Caracterização gravimétrica}

0 estado da Bahia foi objeto de vários levantamentos gravimétricos regionais, tais como os da Petrobras nas bacias do Recôncavo-Tucano-Jatobá (Petrobras, 1969, 1970), e os da CPRM e IAG/USP em grandes áreas do estado (Gomes \& Mota, 1980; Molina et al., 1997; CPRM, 2006). 0 Observatório Nacional (ON) também tem realizado medidas gravimétricas absolutas para compor a rede nacional de estações gravimétricas (RENEGA). Algumas das estações da RENEGA foram usadas para a calibração do levantamento aqui enfocado.

Um amplo levantamento gravimétrico regional foi efetivado para auxiliar na análise da estrutura geológica do aquífero Urucuia e de seu substrato, na área do entorno das bacias estudadas. Este levantamento foi realizado conjuntamente com um levantamento geodésico usando GPSs diferenciais, visando uma definição mais acurada das coordenadas geográficas das estações de medição.
No total, foram levantadas 565 estações, conforme ilustrado na Figura 4. Os dados gravimétricos foram obtidos usando dois gravímetros de marca Lacoste-Romberg e, de um terceiro, da marca Scintrex.

0 levantamento envolveu um total de 85 dias de trabalho de campo, com pelo menos duas equipes trabalhando simultaneamente. A área de trabalho foi subdividida em 10 quadrículas de $1 / 2$ grau de lado, referidas no mapeamento do IBGE na escala de 1:100.000, pelas seguintes denominações: Guarani de Goiás, Rio Arrojado, Arrojolândia, Gatos, Posse, Lagoa do Pratudão, Vereda Funda, Rio Itaquari, Damianopólis e Lagoa do Formoso. Dentro de cada uma delas se estabeleceu um número médio de 50 estações de geodésia e gravimetria, regularmente espaçadas em cerca de $8 \mathrm{~km}$ entre si. 0 sistema de referências adotado para todo 0 levantamento geodésico foi o WGS-84.

0 posicionamento em campo das estações de levantamento foi efetuado com GPSs diferenciais usando transferências geodésicas de estações complementares a partir de marcos de referência do IBGE referidos como SAT-93080, SAT-91655 e SAT-93168. Foram normalmente utilizados dois equipamentos GPSs, sendo um fixado numa estação da rede altimétrica do IBGE ou numa estação fixa transferida para cada quadrícula, e um móvel, ao longo dos caminhamentos. Foram usadas leituras contínuas com 20-30 minutos de amostragem temporal dos sinais de satélites em cada estação, de modo que a acurácia planimétrica e altimétrica alcançada foi inferior a $5 \mathrm{~m}$ nas coordenadas geográficas, e a $10 \mathrm{~cm}$ na altitude elipsoidal.

Os dados dos registros automáticos obtidos com os GPSS diferenciais foram devidamente processados, usando os "softwares" comerciais de ajuste Track-maker e Ashtech Solutions. Para converter os dados altimétricos referidos ao elipsoide WGS84 para altitudes ortométricas ou geoidais foi utilizado o seguinte procedimento. Através do aplicativo MAPGE0-2004, desenvolvido pelo IBGE, calculou-se o valor da ondulação geoidal $(N)$ de cada estação de medição. A altitude geoidal $(H)$ de cada estação foi então calculada pela expressão $H=h-N$, com $h$ sendo a altitude elipsoidal. As altitudes finais obtidas podem ter variações de $1 \mathrm{~m}$, de acordo com a precisão do mapa geoidal construído pelo IBGE em torno da área do projeto.

Na obtenção dos dados gravimétricos foram utilizadas as estações de Santana e de Santa Maria da Vitória, que fazem parte da Rede Gravimétrica Brasileira, e as de Correntina e Posse, transferidas pelo CPGG/UFBA utilizando, nas operações de transferência, três ocupações intermediárias em períodos de tempo de menos de 12 horas. Dessa forma, a acurácia geral dos dados gravimétricos obtidos é inferior a 0,1 mGal.

As leituras gravimétricas com o sistema CG3M foram realizadas com 120 medidas a cada segundo, com atualização de média 


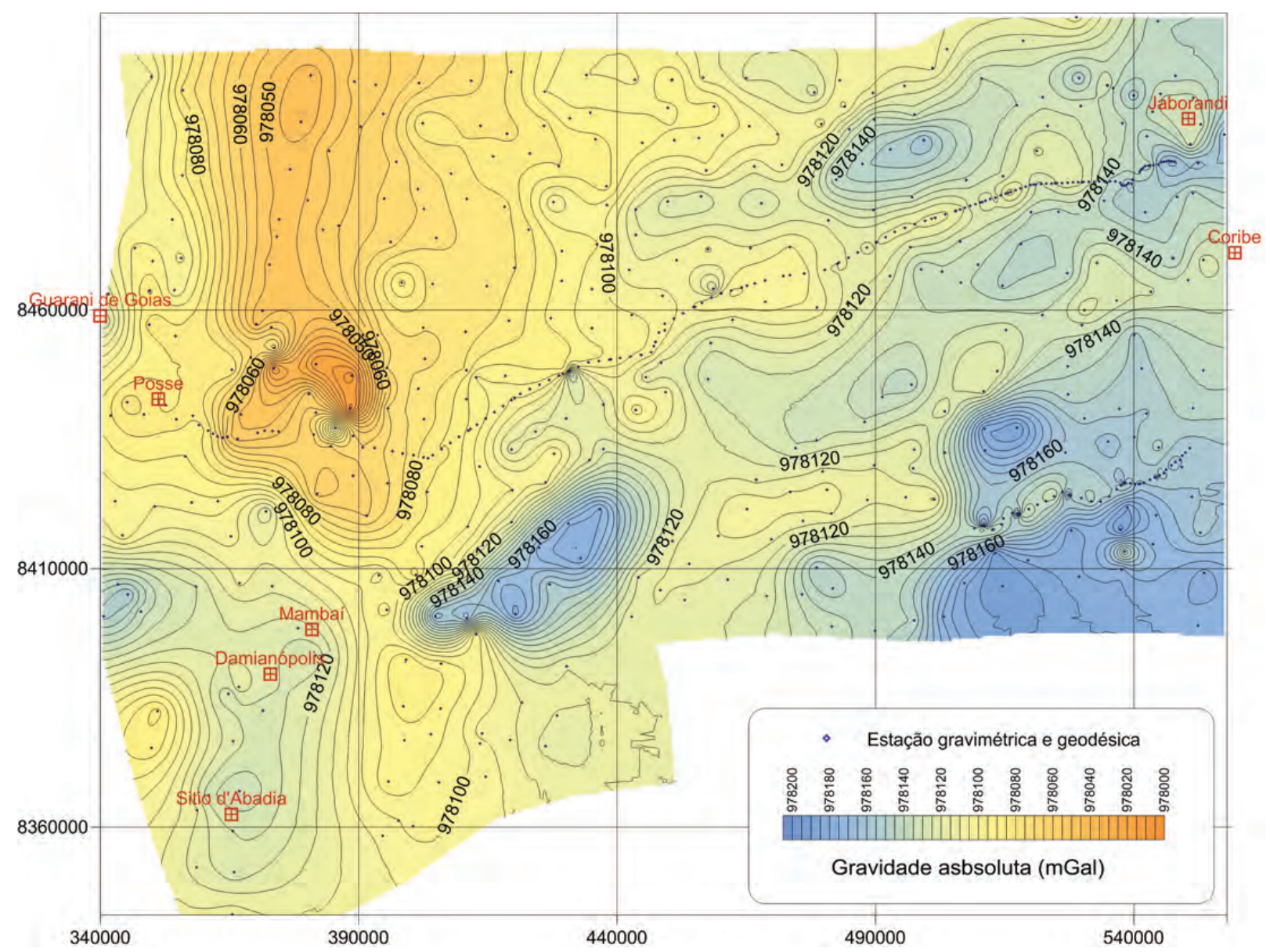

Figura 4 - Mapa de isovalores da gravidade absoluta na área das sub-bacias dos rios Arrojado e Formoso.

e desvio-padrão a cada 12 medidas. 0 equipamento efetua automaticamente as correções de deriva, de maré e de inclinação das bolhas de nível $X$ e $Y$. Os valores de gravidade observados em cada estação com os Lacoste-Romberg foram inicialmente corrigidos para as seguintes variações sistemáticas e temporais: constante de calibração instrumental, altura da base do instrumento, derivas estáticas e dinâmicas, e efeitos das marés terrestres. No cálculo da anomalia Bouguer foram incluídas as correções da gravidade teórica local e as variações de ar-livre e da placa Bouguer, usando um valor de densidade média estimada para as rochas sedimentares de $2,56 \mathrm{~g} / \mathrm{cm}^{3}$.

As correções de latitude, de ar-livre e de Bouguer foram aplicadas aos dados medidos de gravidade absoluta para obter valores de gravidade Bouguer através da expressão,

$$
g_{B}=g_{A}-g_{T}+c_{B}
$$

onde, $g_{B}$ corresponde ao valor da gravidade Bouguer, $g_{A}$ é 0 valor medido da gravidade absoluta, $g_{T}$ representa a gravidade teórica na latitude $\varphi$, em radianos, e $c_{B}$ representa as correções de ar-livre e de Bouguer conjuntamente. 0 valor da gravidade

$$
\begin{aligned}
g_{T}= & 978031,85\left(1+0,005278895 \operatorname{sen}^{2} \varphi\right. \\
& \left.+0,000023462 \operatorname{sen}^{4} \varphi\right),
\end{aligned}
$$

enquanto o fator combinado de correção $c_{B}$ é dado por

$$
c_{B}=(0,3086-2,56 \times 0,04185) H,
$$

para pontos situados a uma elevação ortométrica $H$ e uma cobertura sedimentar com densidade de $2,56 \mathrm{~g} / \mathrm{cm}^{3}$.

A correção de terreno é normalmente realizada subdividindo a região em torno de cada estação por pequenos corpos de geometria simples, de modo a calcular facilmente sua atração. Usando os dados altimétricos geoidais foi construído um modelo digital do terreno para a área levantada, o qual foi estatisticamente calibrado usando o pacote Dapple da Geosoft e uma imagem DTM construída com dados de satélites georreferenciados. As correções descritas acima, em sua forma final, foram efetuadas 
em computador, utilizando o software Oasis montaj v 4.2 licenciado pela Geosoft para o CPGG/UFBA.

Os valores absolutos da gravidade observada nas 565 estações da área de estudo estão apresentados na forma de um mapa de contorno com imagem a cores na Figura 4. Esses resultados foram computados e representados graficamente usando 0 software SURFER 8. 0 mapa das anomalias gravimétricas Bouguer construído do mesmo modo, consta da Figura 5. Na reamostragem e interpolação dos dados das Figuras 4 e 5 foi usado o procedimento estatístico da krigagem com o programa SURFER, com uma malha regular de $500 \mathrm{~m}$ de separação nas coordenadas horizontais. No processamento usando Oasis montaj foi efetuada uma análise de dependência espacial mais rigorosa dos dados, com determinação de variogramas para melhor controlar o processo de krigagem. Não observou-se grandes modificações entre os mapas resultantes.

$\mathrm{Na}$ Figura 4 verifica-se que os valores mais baixos de gravidade ocorrem no setor noroeste do mapa, quase que demarcando o limite da Serra Geral de Goiás. Os valores crescem, em geral, de noroeste para sul e sudeste, com oscilações locais ligadas a flutuações na profundidade do substrato cristalino mais denso. No mapa de anomalias Bouguer (Fig. 5), construído após as correções de ar-livre, Bouguer, e das irregularidades do terreno, observa-se melhor as irregularidades na topografia do embasamento, assim como a orientação geral dos principais lineamentos estruturais.

Na Figura 6 estão mostradas as anomalias residuais produzidas pelas rochas e estruturas dominantes nas coberturas sedimentar e metassedimentar do embasamento cristalino, cujo efeito foi reduzido supondo um comportamento regional aproximado por um polinômio de primeiro grau. Nesse mapa estão demarcados os principais lineamentos do tipo falha, inferidos da geometria das anomalias. Observa-se que tais lineamentos praticamente coincidem com linhas da drenagem superficial, suportando a hipótese de que as mesmas seriam estruturalmente controladas.

A definição quantitativa da estrutura de blocos falhados está representada nos três perfis transversais apresentados nas Figuras 7 a 9 (ver localização na Fig. 4). Na Figura 7 é mostrado o perfil A-A', construído transversalmente às direções inferidas dos falhamentos principais na parte ocidental da área. 0 perfil B-B' (Fig. 8) é transversal à direção de falhamentos secundários, na parte central do mapa. 0 perfil C-C' cruza a parte oriental do mapa, sendo também transversal à direção dos falhamentos principais. Esses perfis foram interpretados e ajustados numericamente com a aproximação bidimensional de Talwani usando o programa GMSYS incluído no pacote Oasis montaj.
No ajuste dos perfis invertidos foram usados os seguintes valores de densidade para as principais unidades litológicas do preenchimento sedimentar/metassedimentar: (i) para os depósitos do Grupo Urucuia adotou-se o valor de $\rho_{u}=2,56 \mathrm{~g} / \mathrm{cm}^{3}$, estimado usando os perfis de porosidade efetiva; (ii) para os metassedimentos do Grupo Bambuí, $\rho_{b}=2,63 \mathrm{~g} / \mathrm{cm}^{3}$, conforme estimado por Marinho (1977) para depósitos desse grupo na Chapada Diamantina; (iii) para as rochas do embasamento cristalino do Cráton do São Francisco, $\rho_{c}=2,90 \mathrm{~g} / \mathrm{cm}^{3}$. A espessura total de sedimentos/metassedimentos nos perfis de oeste é da ordem de $3.000 \mathrm{~m}$, enquanto no perfil de leste varia de $400 \mathrm{~m}$ a mais de $3.000 \mathrm{~m}$.

\section{Caracterização geoelétrica}

Sondagens elétricas de resistividade foram realizadas em 65 centros selecionados, a maioria deles localizada ao longo das rodovias principais e secundárias, com uma distribuição espacial definida para cobrir, o mais regularmente possível, toda a extensão areal da bacia (Fig. 10). Essas sondagens foram obtidas com 0 arranjo Schlumberger de eletrodos, expandido até a máxima separação de $1.000 \mathrm{~m}$, com os equipamentos SYSCAL R-2 e SYSCAL-PRO fabricados pela Iris Instrument. Os dois sistemas SYSCAL possuem potência de $250 \mathrm{~W}$, são alimentados por baterias comuns de $12 \mathrm{~V}$, que são acopladas a conversores DC-DC capazes de produzir tensões máximas de saída de 800 e $1000 \mathrm{~V}$, respectivamente. Como eletrodos de corrente e de potencial foram usadas barras de aço, revestidas com cobre, enterradas no máximo $50 \mathrm{~cm}$ no terreno. Para reduzir as altas resistências de contatos entre os eletrodos e o terreno, os buracos de aterramento foram sempre molhados com água bastante salgada.

Mais de uma dezena das sondagens foram centradas próximas a poços de produção de água para, através dos vínculos de profundidades do nível estático e de algumas interfaces marcantes, auxiliarem na redução da ambiguidade da interpretação geoelétrica final. As curvas das funções resistividade aparente $\left(\rho_{a}\right)$ foram automaticamente invertidas usando modelos unidimensionais de terra e procedimentos de ajuste não-linear por mínimos quadráticos entre os dados observados e os valores calculados (Vozoff, 1958; Koefoed, 1979).

A Figura 11 é uma representação da variação espacial da função resistividade aparente observada para a separação de eletrodos $A B / 2$ de $100 \mathrm{~m}$. Ela reflete, principalmente, as variações laterais localizadas na parte superior do sistema aquífero Urucuia. Nele destacam-se três zonas de comportamentos geoelétricos: (i) na primeira, correspondente à parte oriental do mapa, os va- 


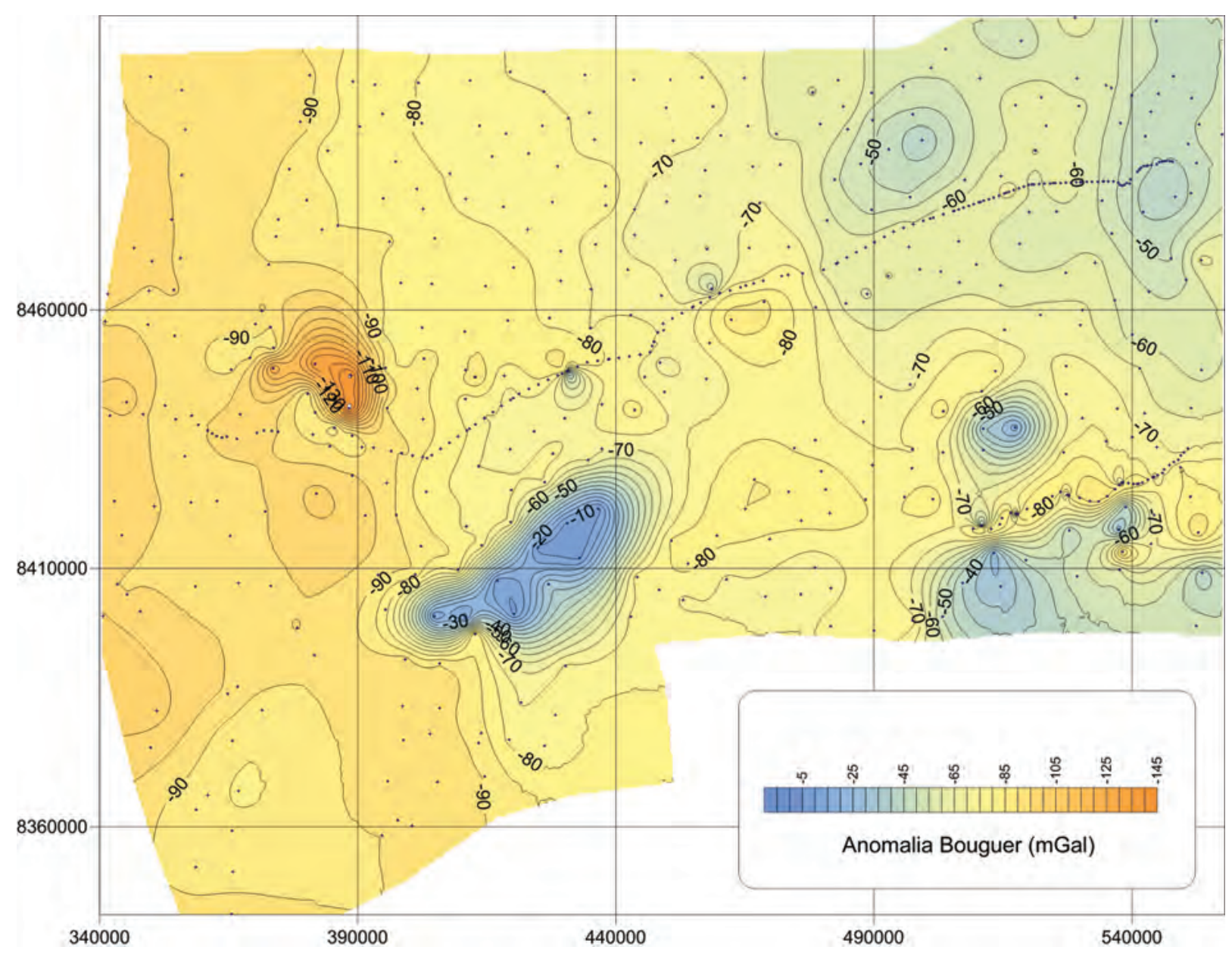

Figura 5 - Mapa das anomalias gravimétricas Bouguer na área das sub-bacias dos rios Arrojado e Formoso.

lores de $\rho_{a}$ variam entre 6.000 e $10.000 \Omega$.m. Essa zona corresponde à parte mais espessa do sistema e os valores mais baixos devem-se a presença de maiores espessuras da Formação Serra das Araras; (ii) uma zona intermediária, onde $\rho_{a}$ varia de 10.000 a $15.000 \Omega$.m, dominada por arenitos mais limpos da Formação Posse; e (iii) uma zona de resistividades mais elevadas na parte nordeste do mapa (15.000 a $20.000 \Omega$.m), em áreas de menores espessuras do sistema. Tais aumentos no valor de $\rho_{a}$ podem estar relacionados a uma maior silicificação dos arenitos nesse setor. Além disso, a presença de zonas com linhas de contornos fechadas, sugerem a existência de contrastes laterais de resistividade, possivelmente associados a falhas regionais.

Praticamente todas as sondagens elétricas efetuadas na área apresentam comportamento regular e suave, compatível com modelos estratificados de camadas sub-horizontais. Todavia, devido a variações laterais na resistividade elétrica do solo mais superficial, algumas dessas curvas apresentam fortes deslocamentos de ramos quando da mudança dos eletrodos de potencial $\mathrm{M} \mathrm{e}$ $\mathrm{N}$, conforme representado na Figura 12. Para essas situações, foi aplicado um processamento de redução, de modo a deslocar numericamente os ramos afetados por quantidades constantes, conforme mostra-se na Figura 13.

Todas as sondagens elétricas executadas foram invertidas unidimensionalmente usando os softwares: (i) RES1D da Geotomo Softwares, para compor modelos estruturais iniciais a serem submetidos à inversão; (ii) RESIST 1.0, programa de domínio público elaborado por Vander Velpen \& Sporry (1993) para efetuar a inversão não-linear por mínimos quadráticos.

A maioria das curvas de sondagens obtidas tem a forma de uma dupla de colinas com uma depressão central refletindo, basicamente, as variações litológicas no Grupo Urucuia. As colinas correspondem a pacotes arenosos mais limpos, sendo a primeira geralmente correspondente à zona não-saturada do aquífero. A depressão central deve-se a uma redução na resistividade do 


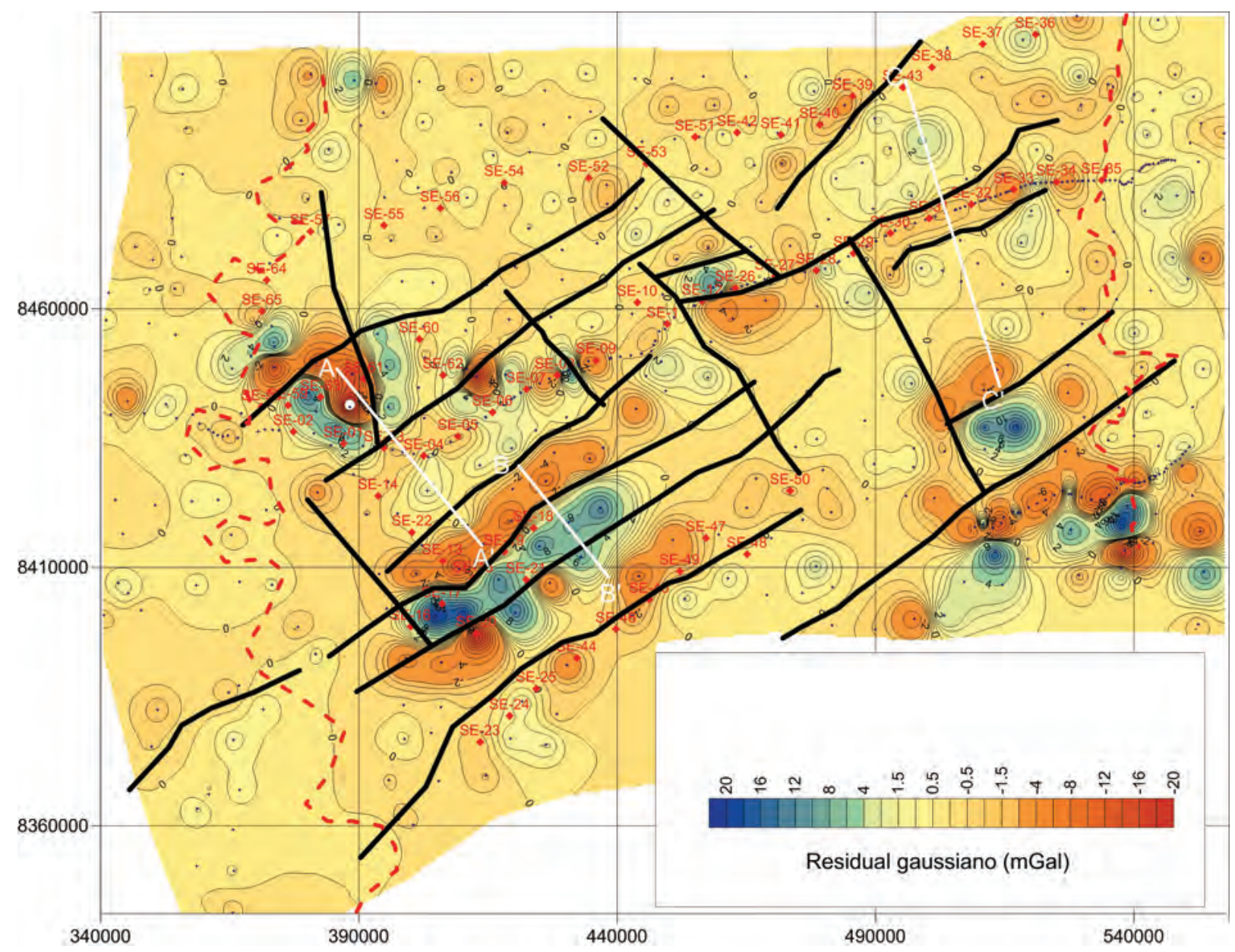

Figura 6 - Mapa de anomalias gravimétricas residuais na área das sub-bacias dos rios Arrojado e Formoso com indicação dos perfis interpretados.

aquífero, associada a um aumento na argilosidade, característico da Formação Serra das Araras. Quase todas as sondagens apresentam ramos terminais descendentes, indicando a existência de um pacote regional muito mais condutor, interpretado como a Formação Geribá acoplada às litologias meta-argilosas do substrato Bambuí, suportando os pacotes mais arenosos.

As Figuras 14 e 15 contêm gráficos representativos de algumas das sondagens elétricas invertidas unidimensionalmente usando os procedimentos computacionais mencionados (Vozoff, 1958; Koefoed, 1979). Em geral, apesar dos contrastes de resistividade elevados entre os diferentes horizontes da subsuperfície, as inversões foram satisfatórias em função do uso das informaç̃oes de controle disponíveis. Nas sondagens paramétricas, os dados de $\rho_{a}$ foram ajustados, com erros médios quadráticos inferiores a $2 \%$, fixando-se a profundidade do nível freático e ajustando-se os valores de resistividade das camadas até um limite de erro prefixado de 1\%. Os dados observa- dos (símbolos coloridos nos gráficos) ajustam-se com muito boa precisão às curvas teóricas computadas para os modelos geoelétricos interpretados (curvas cheias).

Quatro seções geoelétricas transversais formadas por SEVs, equidistantes em média de 8 km, são usadas para representar a estrutura geológica regional da área (ver localização das seções no mapa da Fig. 10). As Figuras 16 e 17 mostram as seções transversais A-A' e B-B', construídas, respectivamente, com $9 \mathrm{e}$ 10 SEVs obtidas ao longo da rodovia Posse-Correntina, que é orientada de sul-sudoeste para nordeste-leste. As duas seções combinadas mostram que a sequência arenosa superior do Grupo Urucuia é bem delgada no extremo leste do perfil, mas espessa-se, progressivamente, em direção a oeste, podendo alcançar, próximo à escarpa da Serra Geral, mais de $500 \mathrm{~m}$ de espessura (Fig. 16). 0 substrato do sistema aquífero é invariavelmente representado como um pacote muito condutor que, por controle dos dados dos poços M0-02 e PE-01, é interpre- 

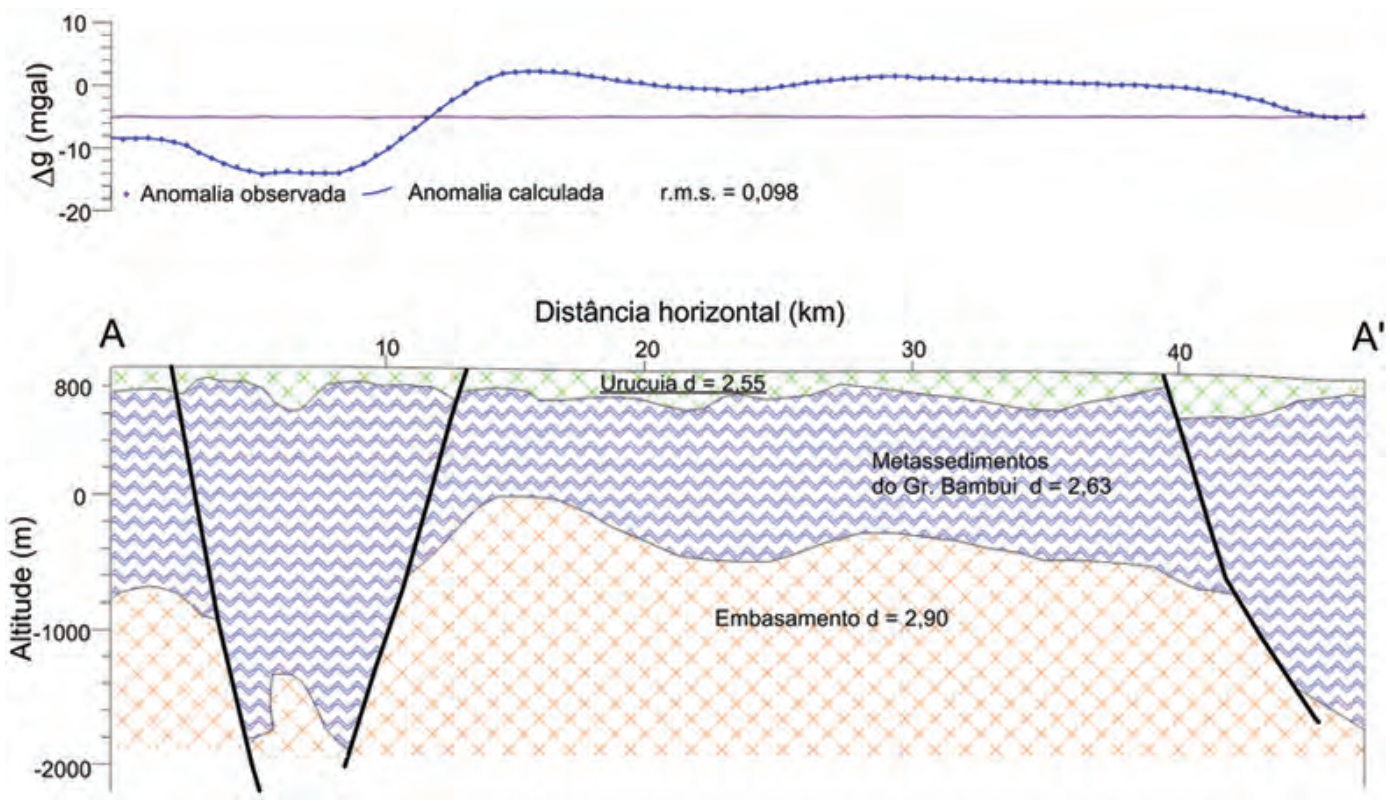

Figura 7 - Perfil gravimétrico residual A-A' e modelo geofísico-geológico interpretado.
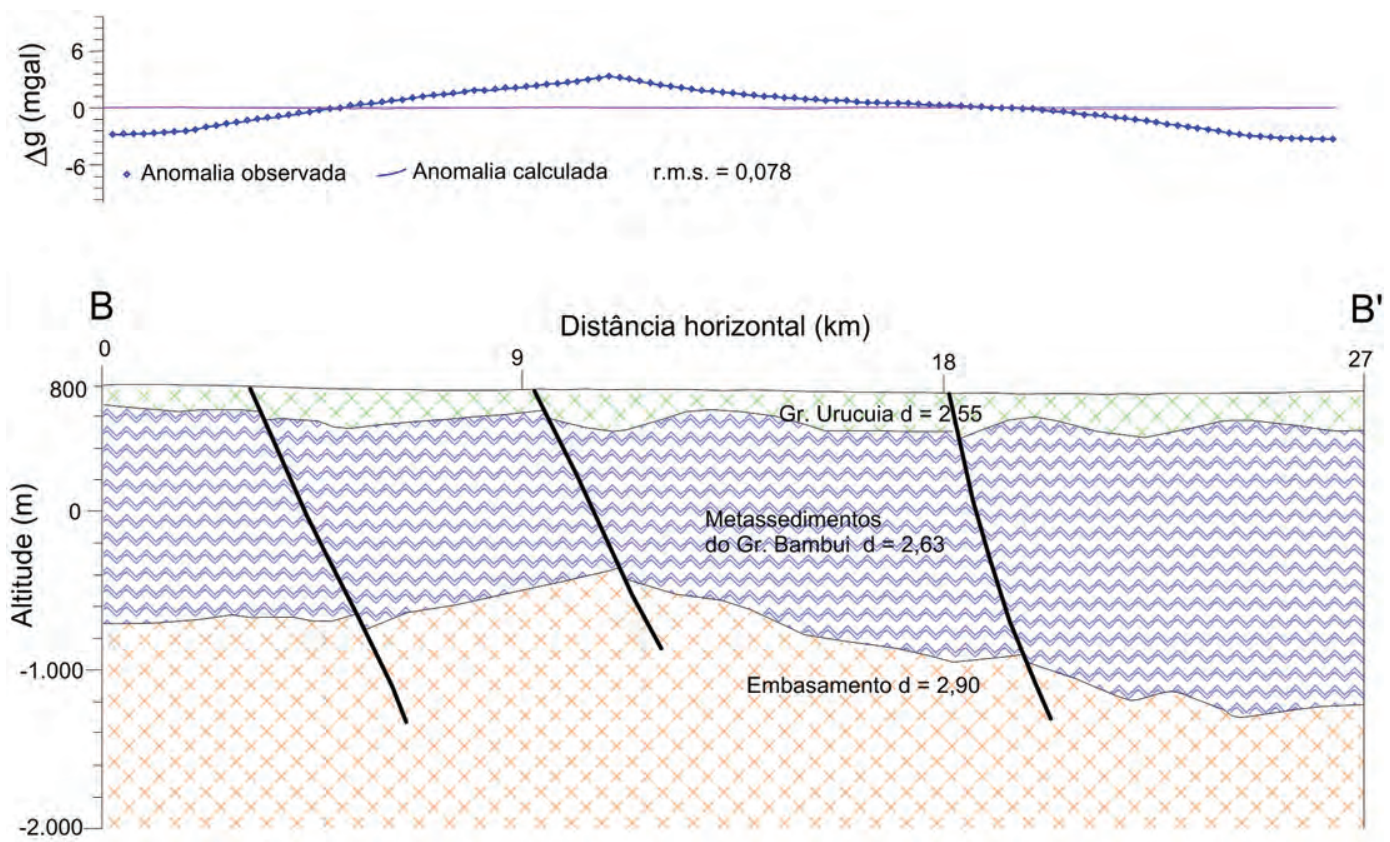

Figura 8 - Perfil gravimétrico residual B-B' e modelo geofísico-geológico interpretado.

tado corresponder à sequência argilosa da Formação Geribá, em geral eletricamente acoplada às rochas meta-argilosas do Grupo Bambuí. Na seção da metade da área para leste (Fig. 17), este pacote condutor repousa sobre litologias mais resistivas, interpretadas como carbonatos do Grupo Bambuí. A seção da Figura 18 confirma uma situação geológica similar.
Uma expressão da estrutura transversal do sistema Urucuia está mostrada na Figura 19 construída usando dados de oito SEVs. A seção cruza através da parte oeste da sub-bacia, onde 0 pacote arenoso atinge as maiores espessuras. Nesse caso, ao invés de uma estrutura uniformemente inclinada, aparecem duas grandes falhas com deslocamentos diferenciais estimados 

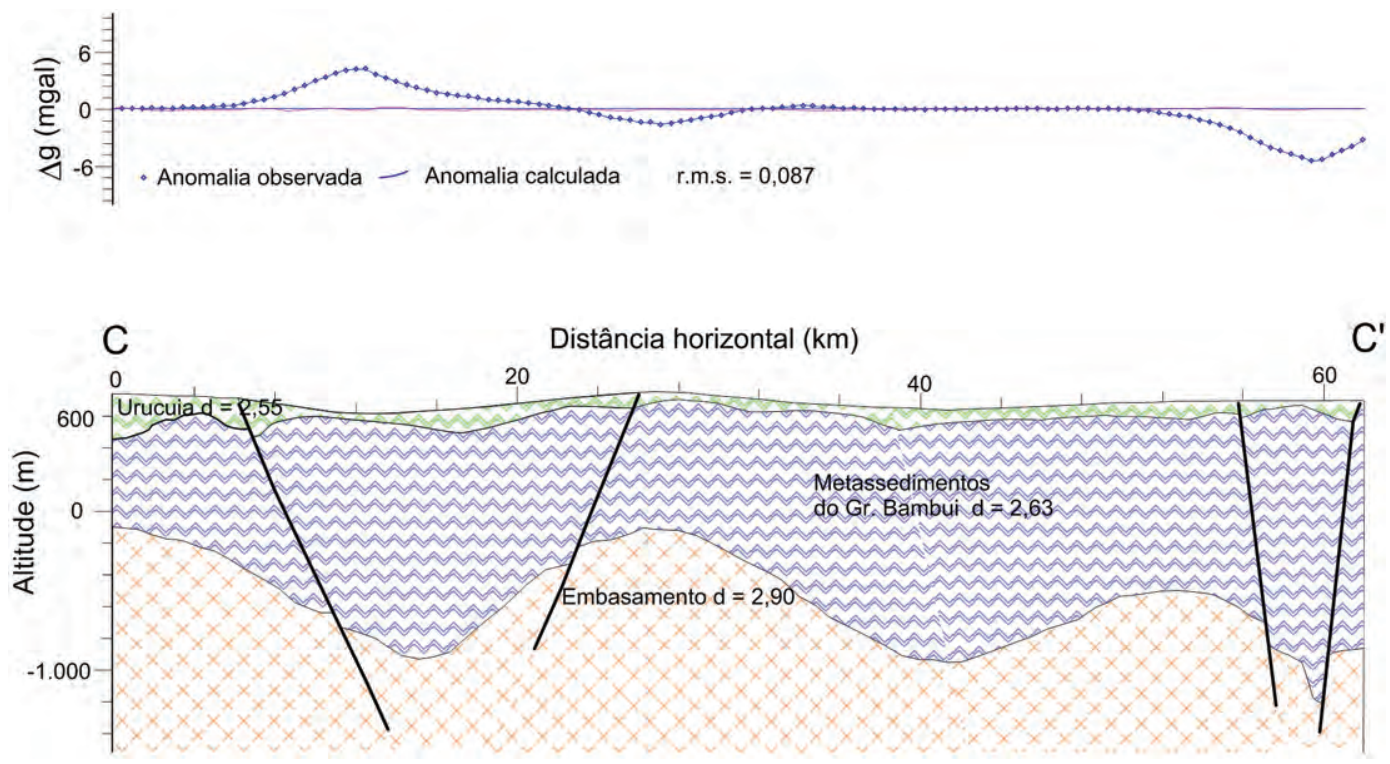

Figura 9 - Perfil gravimétrico residual C-C' e modelo geofísico-geológico interpretado.

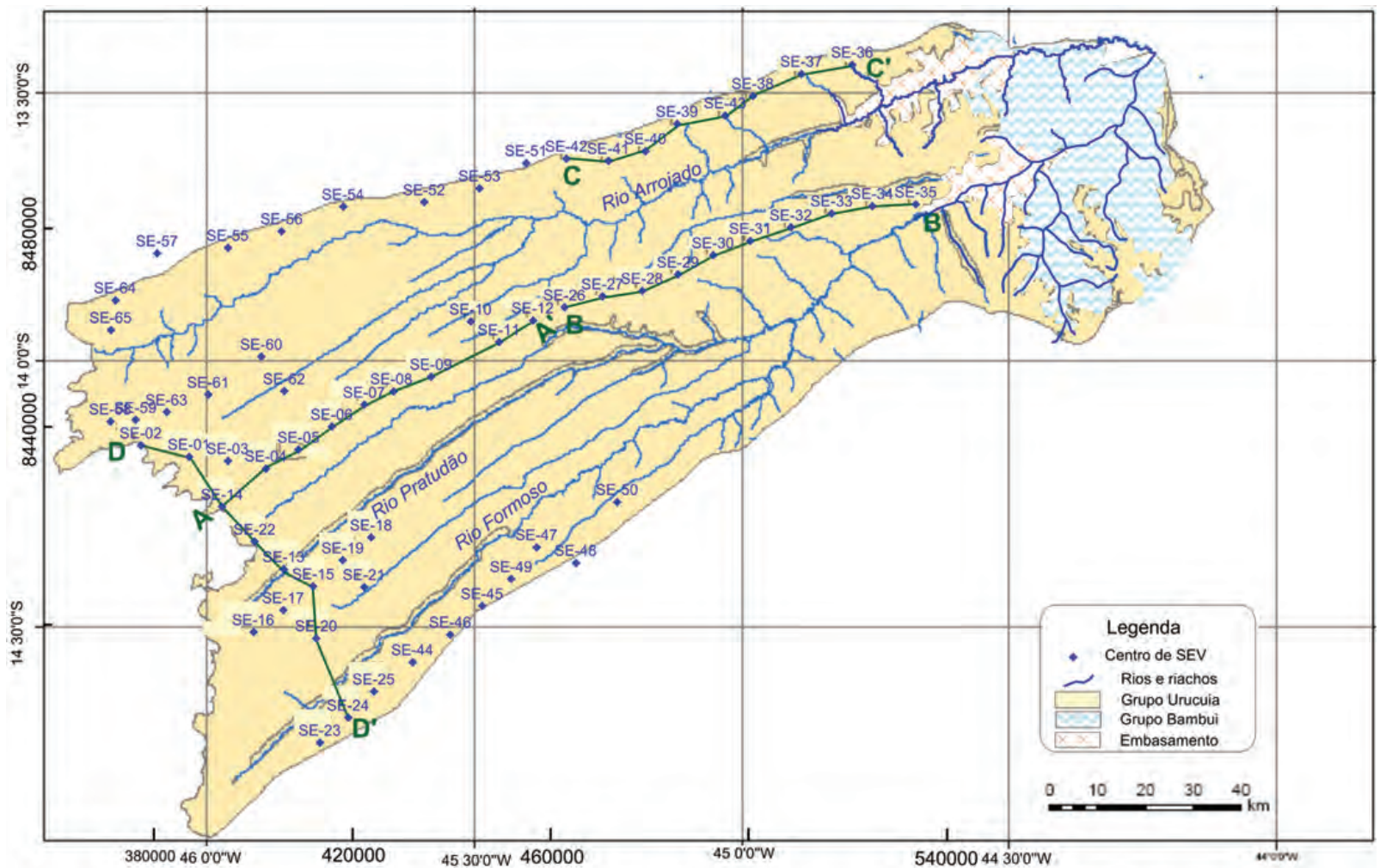

Figura 10 - Mapa geológico da área de estudo contendo a localização dos centros das sondagens elétricas e a orientação das seções geoelétricas A-A', B-B', C-C' e D-D'.

em 100 e 300 m. Essas falhas delimitam um "graben" ao longo do qual o pacote condutor e o substrato representativo do Grupo Bambuí foram soerguidos.
Em todas as seções construídas observa-se que o nível estático das águas subterrâneas varia de menos de $20 \mathrm{~m}$ nas proximidades dos vales, a mais de 180 m próximo à Serra Geral, em 


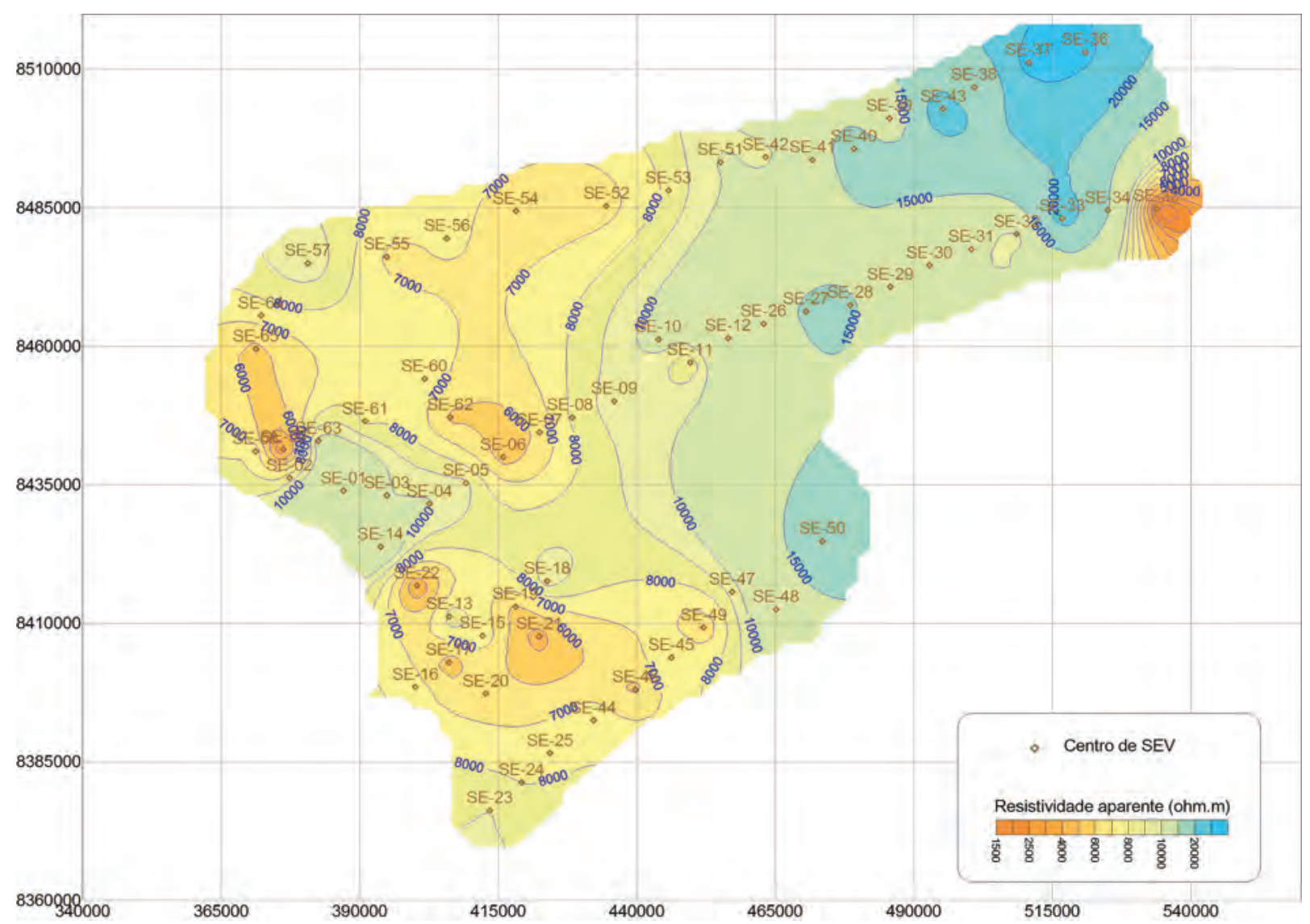

Figura 11 - Mapa da função resistividade aparente para o espaçamento de eletrodos de corrente AB/2 de $100 \mathrm{~m}$.

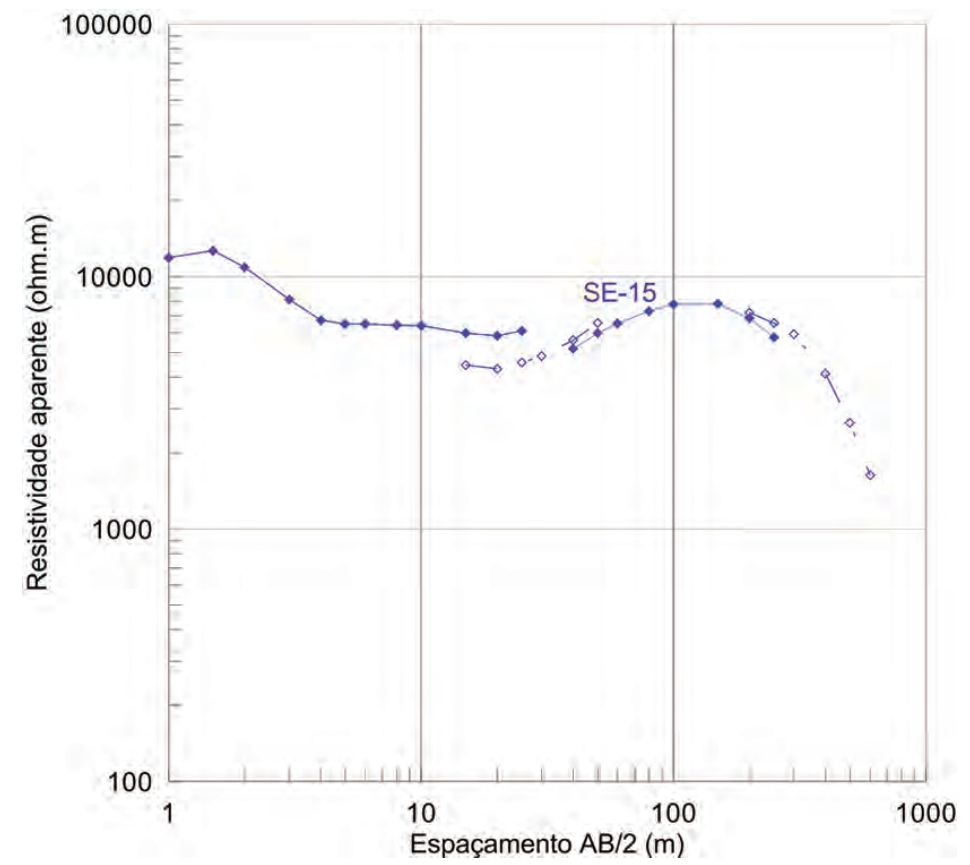

Figura 12 - Dados observados nos quatro ramos da curva da sondagem elétrica SE-15. 


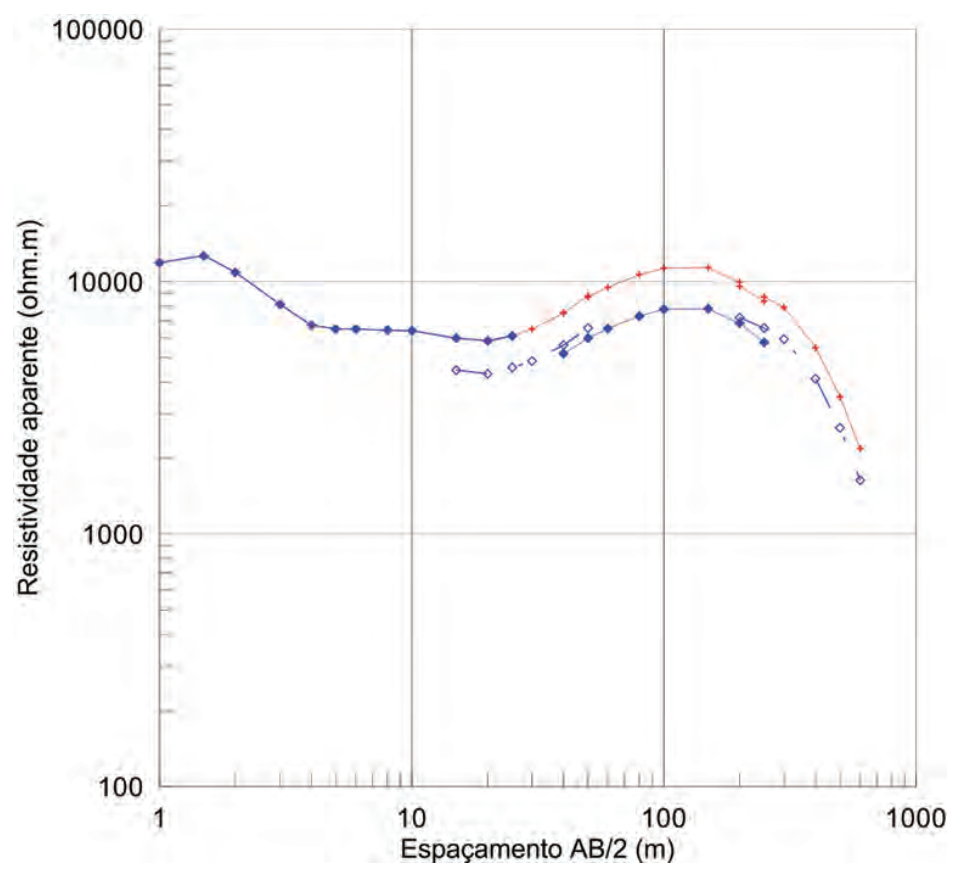

Figura 13 - Dados corrigidos por suavização numérica da curva de sondagem elétrica SE-15.

estreita relação com a topografia do terreno. Tal comportamento atesta um caráter regional não-confinado para o sistema aquífero. Ainda como aspectos hidrológicos importantes, destacam-se: (i) as resistividades elevadas das camadas, em função da baixa salinidade de suas águas, inferior a $200 \mathrm{mg} / \mathrm{l}$, em geral; (ii) a espessa zona vadosa do sistema na parte mais alta do chapadão, que protege suas águas da evapotranspiração; (iii) a presença de um divisor interno no fluxo subterrâneo na bacia, em posição diferente da do divisor das águas superficiais (Figs. 17 e 21).

A disposiç̧ão espacial da superfície freática do aquífero, construída com base nos resultados elétricos, está representada no mapa da Figura 20. As linhas de contorno da elevação hidráulica no aquífero indicam haver, na área estudada, um forte relacionamento entre os fluxos superficial e subterrâneo. Todavia, destacase a presença de uma zona de divergência, orientada praticamente de norte para sul, dividindo o fluxo subterrâneo nas sub-bacias em duas partes: (i) uma, de maior extensão, na qual o fluxo ocorre de oeste para leste, em concordância com a drenagem superficial; (ii) outra, na qual o fluxo se processa em direção a Serra Geral, dirigindo as águas subterrâneas para 0 estado de Goiás.

0 mapa da Figura 21 ilustra a configuração da topografia do substrato condutivo do sistema aquífero (Formação Geribá e Grupo Bambuí). Ele define a orientação estrutural de uma extensa rampa de caimento geral para ENE, acompanhando o caimento da superfície topográfica, perturbada por deslocamentos subver- ticais ao longo de falhas regionais, numa estrutura de blocos faIhados. É inferido que este pacote condutor atue como uma base impermeável para 0 aquífero.

\section{CONCLUSÕES}

Os dados do levantamento gravimétrico regional foram úteis para inferir a espessura do pacote metassedimentar do Grupo Bambuí, que constitui o substrato do sistema aquífero Urucuia, em toda a área do chapadão. Além disso, foram úteis também para mapear e definir estruturas lineares do tipo falhas que parecem ter sido reativadas durante e após a deposição do Grupo Urucuia. 0 padrão estrutural interpretado revela a existência de conjuntos alternados de blocos estruturais elevados e rebaixados.

0 levantamento geolétrico com sondagens verticais objetivou principalmente definir as heterogeneidades litológicas e petrofísicas que caracterizam, também de modo regionalizado, o sistema aquífero Urucuia. Além de variações faciológicas associadas a mudanças de ambiente deposicional e de clima, destaca-se a presença de intensa silicificação detectada tanto em amostras de calha de poços perfurados na área, quanto inferida em perfis geofísicos e em curvas de sondagens elétricas.

Os dados integrados permitiram definir a estrutura geológica regional do sistema aquífero Urucuia e de seu substrato, como a de um pacote permeável acunhado, com espessura saturada 


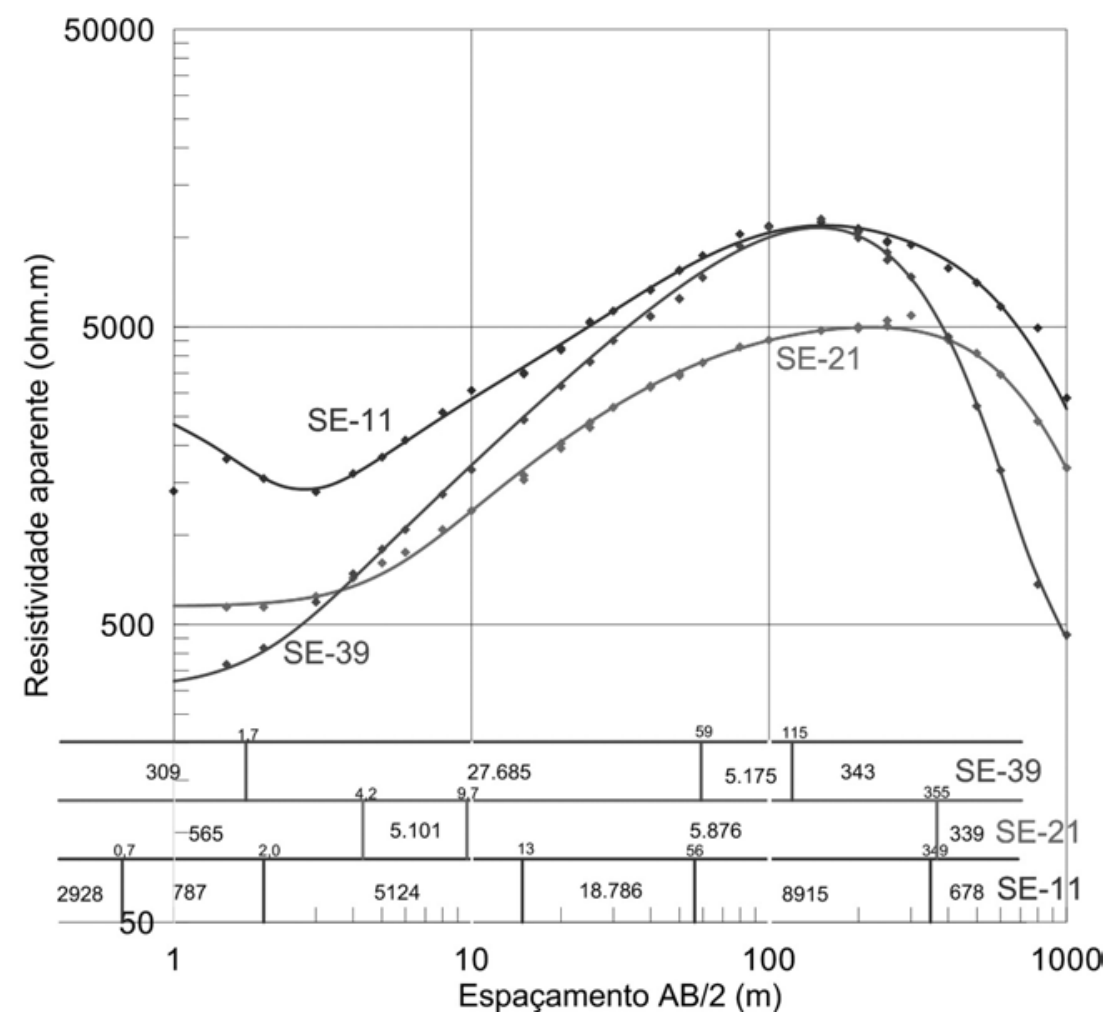

Figura 14 - Exemplos representativos de curvas de sondagens da área e modelos finais interpretados.

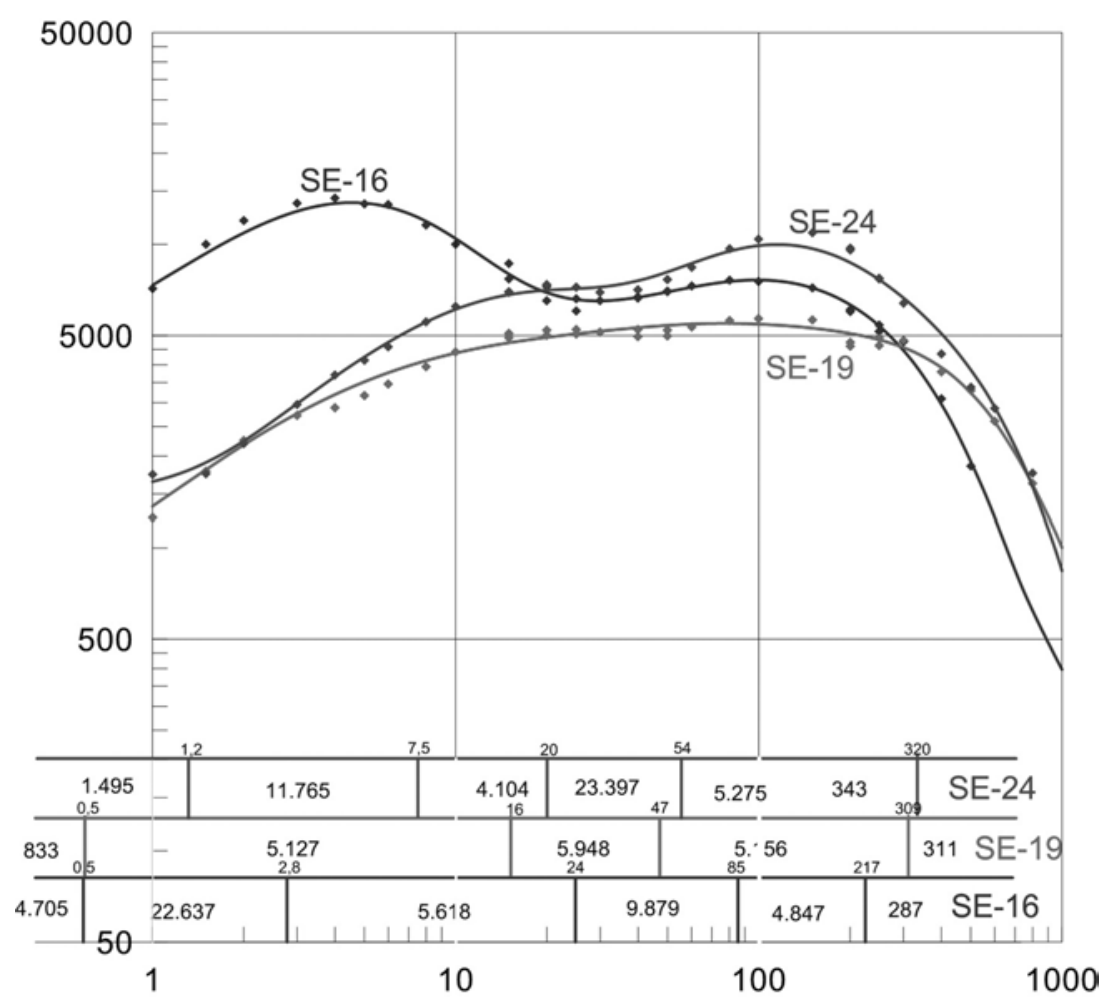

Figura 15 - Exemplos representativos de curvas de sondagens da área e modelos finais interpretados. 


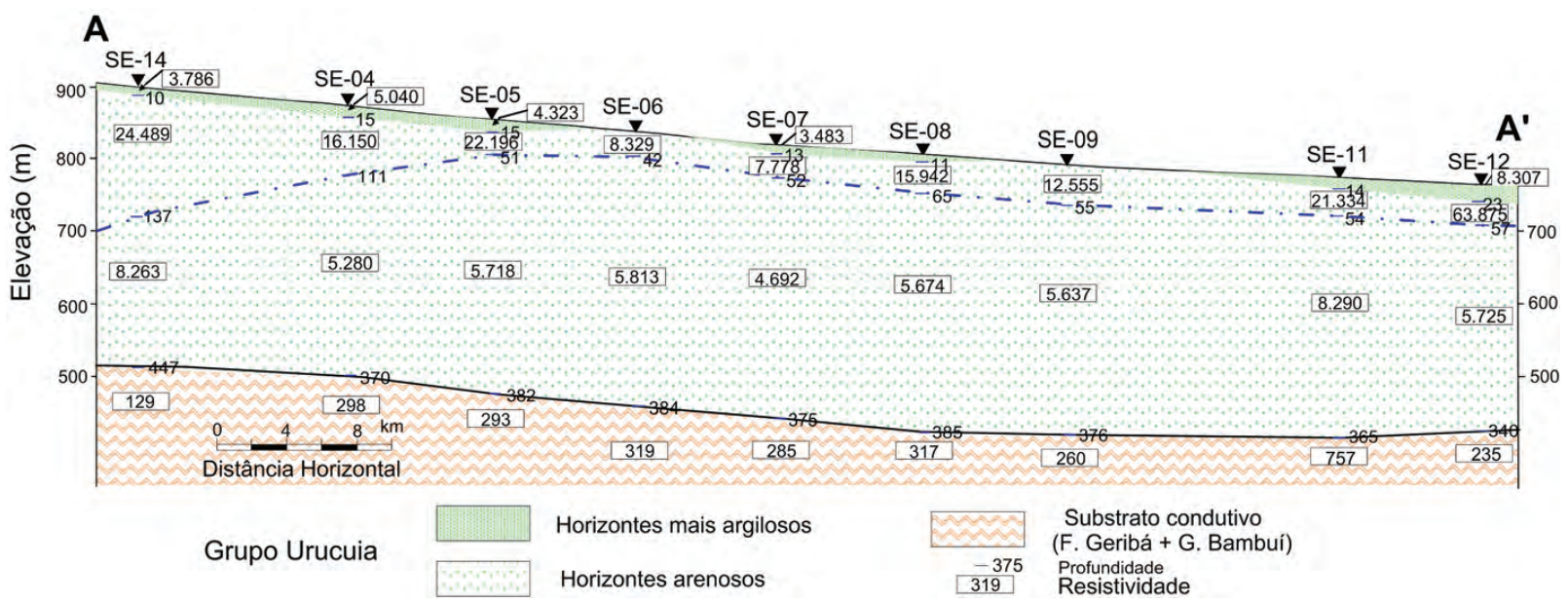

Figura 16 - Seção geológica transversal A-A' construída com base nos dados das sondagens elétricas indicadas.

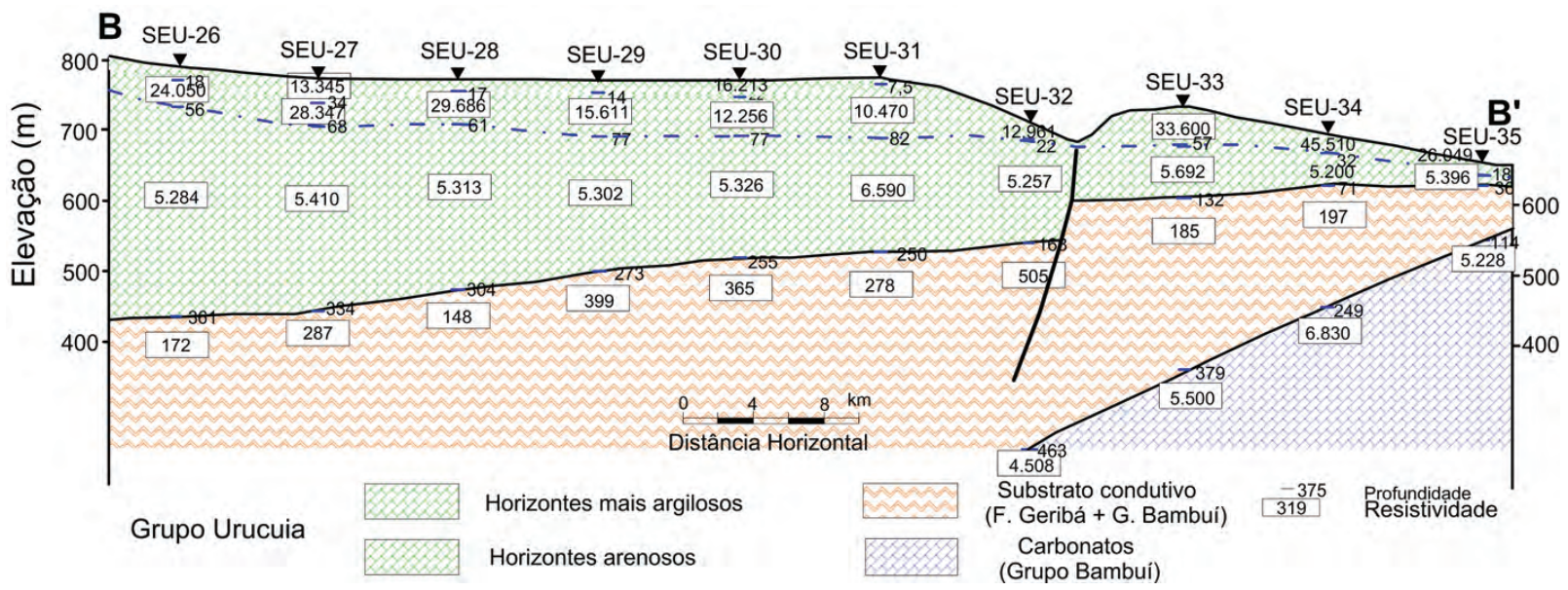

Figura 17 - Seção geológica transversal B-B' construída com base nos dados das sondagens elétricas indicadas.

variando de cerca de $500 \mathrm{~m}$, ao longo de um alto divisor de fluxo, a zero, na porção leste terminal da bacia. Essa cunha sedimentar repousa sobre um espesso substrato, dominantemente meta-argiloso, que pode alcançar $3.000 \mathrm{~m}$ de espessura e que está seccionado por conjuntos de falhas com orientações SW-NE e NNW-SSE.

Os resultados elétricos estão bem controlados por informações hidrogeológicas de poços e serviram de base para orientar a interpretação dos dados gravimétricos.

0 Grupo Urucuia pode alcançar mais de $500 \mathrm{~m}$ de espessura nas proximidades da escarpa da Serra Geral, diminuindo até zero na parte oriental das sub-bacias. Foi aqui proposta sua divisão em três formações geológicas, designadas como Serra das Araras, Posse e Geribá, de características litológicas e geoelétricas distintas. Parece ter sofrido uma tectônica de ruptura, com falhas normais de 0 a mais de $300 \mathrm{~m}$ de rejeito máximo. Tanto a geofísica elétrica quanto a gravimetria revelam a presença de altos e baixos estruturais controlados por tal tectônica.

Dois comportamentos aquíferos distribuídos em profundidade foram identificados na sub-bacia: (i) um sistema de superfície livre, desenvolvido nos intervalos arenosos superiores do Grupo Urucuia; (ii) um sistema parcialmente confinado, nos mesmos arenitos do Urucuia, controlado por intervalos arenosos muito silicificados.

\section{AGRADECIMENTOS}

Os autores agradecem à FINEP/CT-HIDRO pelo financiamento do projeto URUCUIA, dentro da Rede Cooperativa de Pesquisa: Comportamento de Bacias Sedimentares da Região 


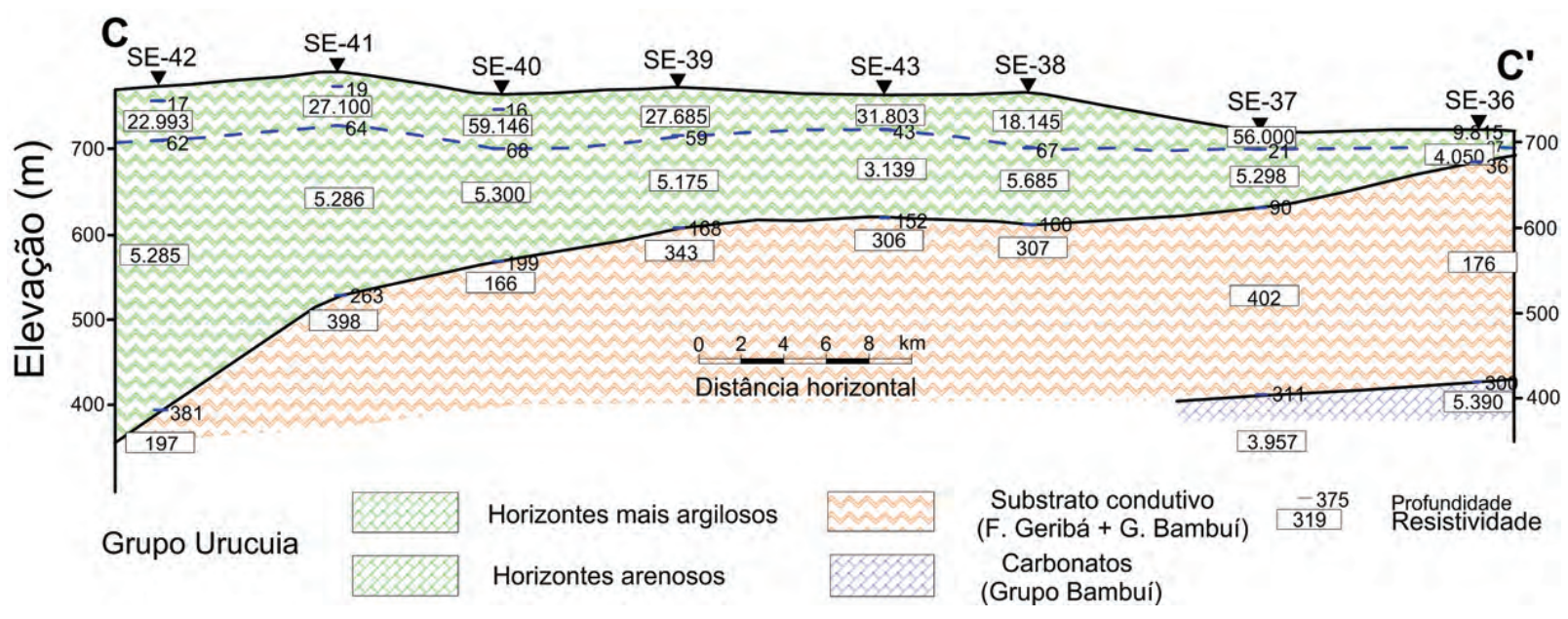

Figura 18 - Seção geológica transversal C-C' construída com base nos dados das sondagens elétricas indicadas.

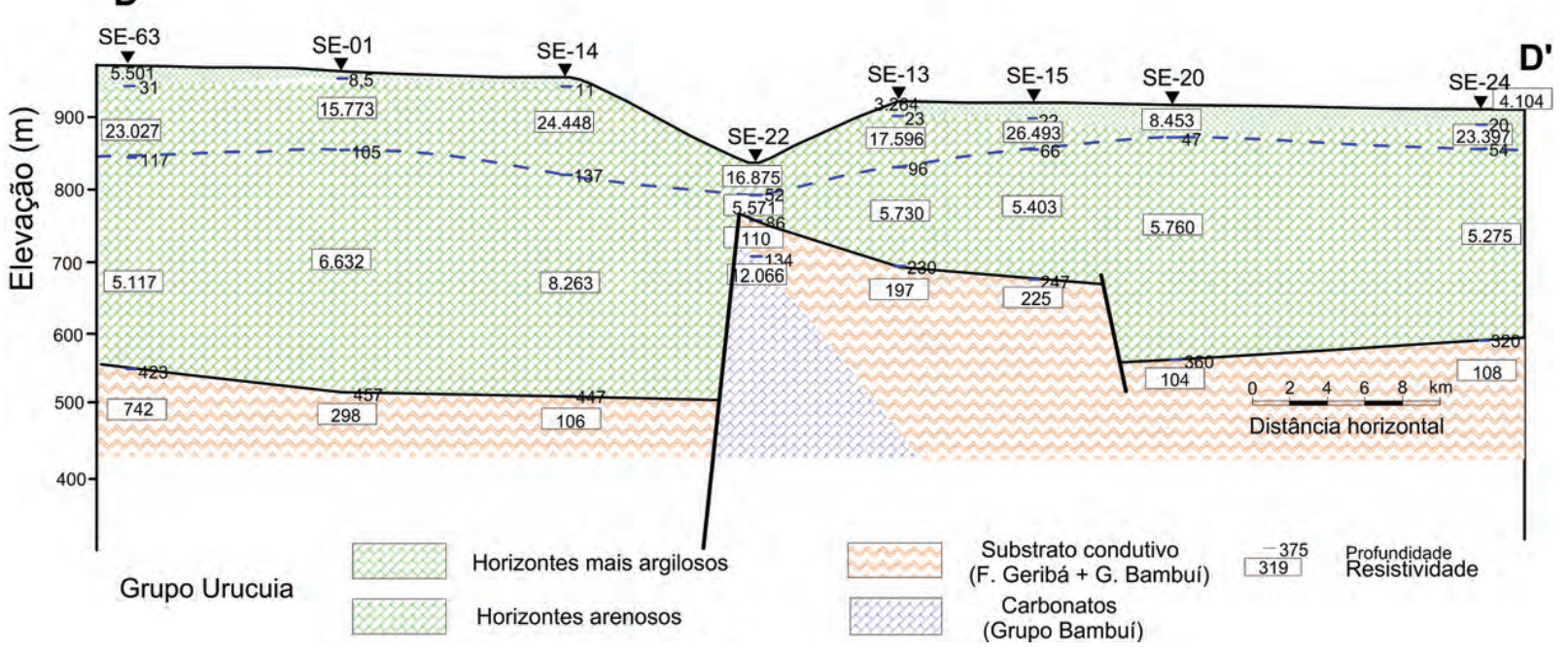

Figura 19 - Seção geológica transversal D-D' construída com base nos dados das sondagens elétricas indicadas.

Semi-Árida do Nordeste Brasileiro. Ao Observatório Nacional/CNPq e ao Centro de Geociências da UFPA pela cessão de gravímetro Lacoste-Romberg e técnico geofísico para sua operação, em apoio à execução do levantamento gravimétrico. Ao CNPq pelas bolsas de produtividade em pesquisa e de mestrado concedidas a Olivar de Lima e Emerson S. dos Santos, respectivamente. Aos técnicos de campo do CPGG/UFBA, José M. dos Santos, Luiz M. dos Santos e José M. da Paz e a equipe da OPA Engenharia, Eng. Antônio R.M. Teles e técnicos Severino S. Simeão e José A. Paixão, pelo empenho na execução dos trabalhos de campo. Ao CPGG/UFBA e à CPRM pelo ambiente e apoio à execução do referido projeto.

\section{REFERÊNCIAS}

ASQUITH GB. 1990. Log Evaluation of Shaly Sandstones: A Practical Guide. Continuing Education Course Note Series \#31, Am. Ass. Pet. Geol., Tulsa, OK, USA.

ASQUITH GB \& GIBSON CR. 1982. Basic Well Log Analysis for Geologists. AAPG Methods in Exploration Series \#3, $216 \mathrm{p}$.

BRASIL. 1982. Projeto RADAMBRASIL, Folha SD 23, Brasília: Geologia, Geomorfologia, Pedologia, Vegetação e Uso da Terra. MME, Rio de Janeiro, RJ.

CAMPOS JEG \& DARDENNE MA. 1997. Estratigrafia e sedimentação da bacia Sanfranciscana. Revista Brasileira de Geociências, 27: 269-282. 


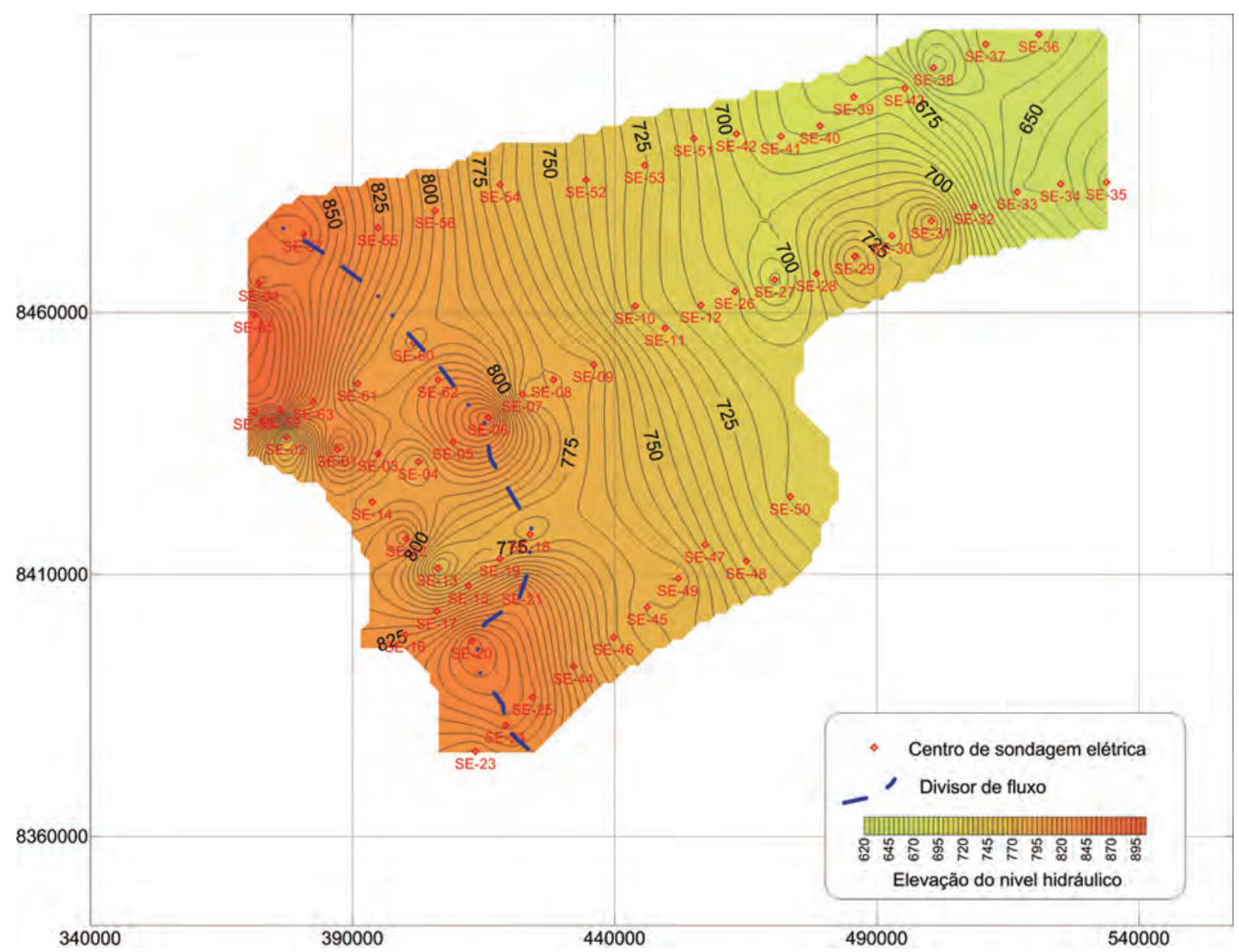

Figura 20 - Mapa de contorno da elevação hidráulica no sistema aquífero Urucuia determinado a partir de dados das sondagens elétricas.

CPRM. 2006. Diagnóstico do Estado da Arte dos Estudos Realizados na Área das Bacias dos Rios Arrojado e Formoso. Serviço Geológico do Brasil, CPRM, Relatório Técnico, Salvador, BA.

DARDENNE MA. 1978. Síntese sobre a estratigrafia do Grupo Bambuí no Brasil Central. In: $30^{\circ}$ Congresso Brasileiro de Geologia, 2: 568-610, São Paulo, SP.

GHIGNONE JI. 1979. Geologia dos Sedimentos Fanerozoicos do Estado da Bahia. In: Geologia e Recursos Minerais do Estado da Bahia, Textos Básicos, v. 1, cap. 3, SME/COM, Salvador, BA.

GOMES RD \& MOTA AC. 1980. Projeto Levantamento Gravimétrico do Estado da Bahia. Serviço Geológico do Brasil, Convênio CPRM/DNPM, Relatório Técnico, Salvador, BA.

KOEFOED 0. 1979. Resistivity Sounding Measurements: Geosounding Principles. Methods in Geochemistry and Geophysics. Elsevier. Amsterdam. $276 \mathrm{p}$.

LIMA EAM \& LEITE EJF. 1978. Projeto estudo global dos recur- sos minerais da bacia sedimentar do Parnaíba: Integração geológicometalogenética. Relatório DNPM/CPRM, 16v., Recife, PE.

LIMA OAL \& SHARMA MM. 1990. A grain-conductivity approach to shaly sandstones. Geophysics, 55: 1347-1356.

LIMA OAL \& SHARMA MM. 1992. A generalized Maxwell-Wagner theory for membrane polarization in shaly sands. Geophysics, 57: 789-799.

LIMA OAL \& SRI NIWAS. 2000. Estimation of hydraulic parameters of shaly sandstones from geoelectrical measurements. Journal of Hydrology, 235: 12-26.

LIMA OAL, SATO HK \& PORSANI MJ. 1995. Imaging industrial contaminant plumes with resistivity techniques. Journal of Applied Geophysics, 34: 93-108.

LIMA OAL, CLENNELL MB, NERY GG \& SRI NIWAS. 2005. A volumetric approach for the resistivity response of freshwater shaly sandstones. Geophysics, 70: F1-F10. 


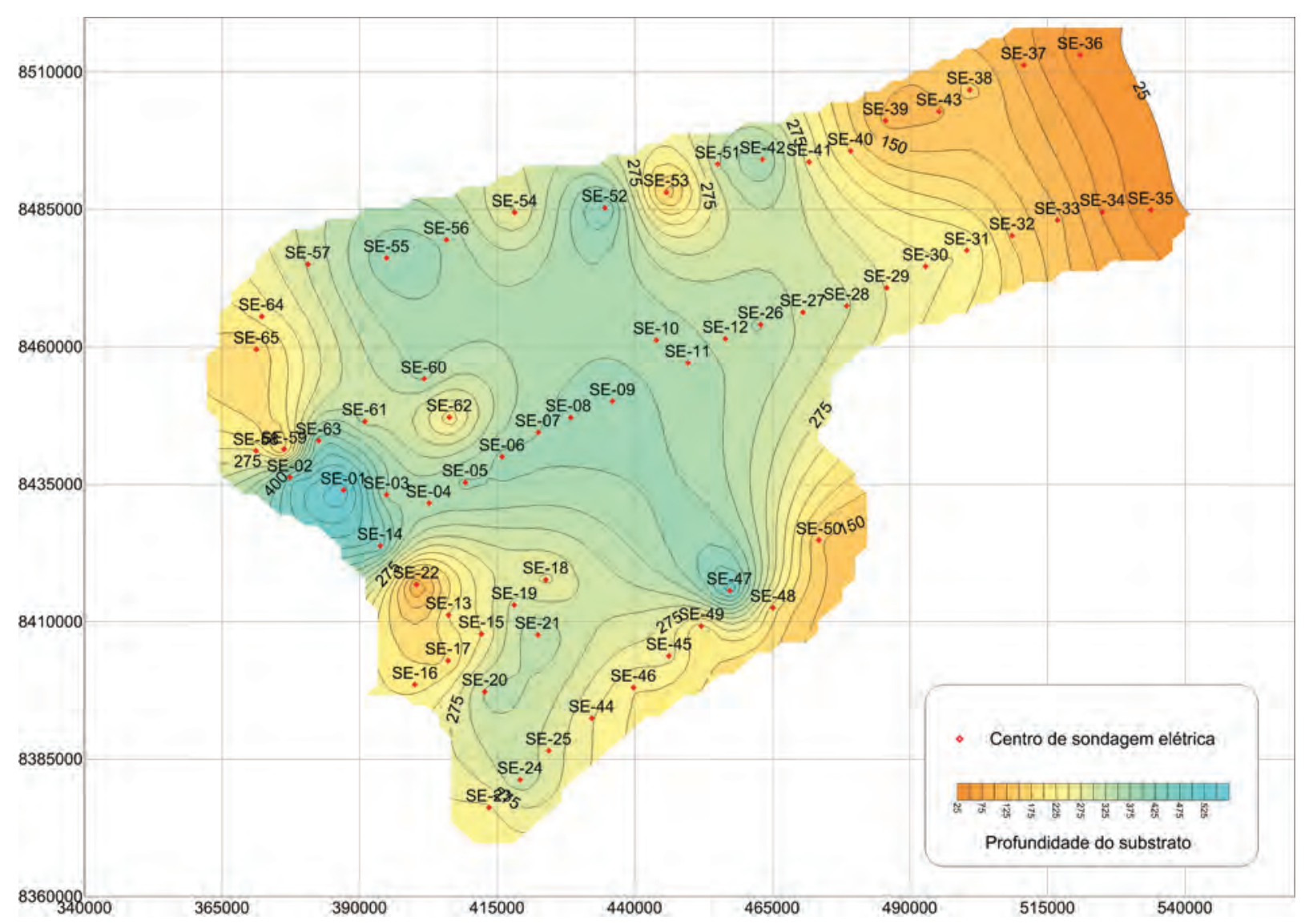

Figura 21 - Mapa de contorno da profundidade do substrato condutor na área das sub-bacias estudadas.

MARINHO JMM. 1977. Reconhecimento geofísico da região de Irecê Bahia. Dissertação de Mestrado em Geofísica, Univ. Fed. Bahia, Salvador. $100 p$.

MEJU MA, FONTES SL, OLIVEIRA MBF, LA TERRA EF, ULUGUGERLI EU \& CARRASQUILLA AG. 1999. Regional aquifer mapping using combined VES-TEM-AMT/EMAP methods in the semi-arid eastern margin of Parnaíba basin, Brazil. Geophysics, 64: 337-356.

MOLINA EC, USSAMI N \& MARAGONI YA. 1997. Digital 5'x $\times 5^{\prime}$ gravity maps of the São Francisco Craton. IAG/USP, Publicação Especial, São Paulo, SP.

MOUTINHO DA COSTA LA, PORTELA ACP, MARCHETTO CML, SANTOS EL, MENEGUESSO G, STEIN JH, BATISTA MB, MOSSMANN R \& SILVA WG. 1976. Projeto Leste do Tocantins/Oeste do rio São Francisco LETOS. Convênio DNPM/CPRM/PROSPEC, Relatório Final Integrado, Rio de Janeiro, RJ.

OLIVEIRA MAM. 1967. Contribuição a geologia da parte sul da bacia do São Francisco e áreas adjacentes. Petrobras, Relatório de Exploração 1 , Rio de Janeiro, RJ.
PETROBRAS. 1969. Levantamentos gravimétricos das bacias do Maranhão, Potiguar, Sergipe-Alagoas, Recôncavo-Tucano. Relatório de Exploração. Rio de Janeiro, RJ.

PETROBRAS. 1970. Mapa Bourger das bacias do Recôncavo e Tucano Sul; Escala 1:100.000. Petrobras DEXBA, Salvador, BA.

SCHLUMBERGER. 1989. Log Interpretation. Principles / Applications. Schlumberger Educational Services, Houston TX, USA.

VANDER VELPEN BPA \& SPORRY RJ. 1993. RESIST. A computer program to process resistivity sounding data on $\mathrm{PC}$ compatibles. Computer \& Geosciences, 19(5): 691-703.

VOZOFF K. 1958 . Numerical resistivity analysis: Horizontal Layers. Geophysics, 23: 536-556.

WARD SH. 1990. Resistivity and Induced Polarization Methods. In: WARD SH (Ed.). Geotechnical and Environmental Geophysics. Society of Exploration Geophysicists, Tulsa OK, USA. p. 147-189.

WYLLIE MRJ, GREGORY AR \& GARDNER LW. 1956. Elastic wave velocities in heterogeneous and porous media. Geophysics, 21: 41-70. 


\section{NOTAS SOBRE OS AUTORES}

Olivar Antônio Lima de Lima. Graduado em Geologia (1967) e Mestre em Geologia Estrutural (1969) pela Universidade Federal do Rio de Janeiro. Doutor em Geofísica (1979) pela Universidade Federal da Bahia. Pós-Doutorado (1989-90) no Departamento de Engenharia de Petróleo da Universidade do Texas, Austin. Professor Titular da UFBA. Áreas de atuação: Aplicação de métodos geofísicos na exploração de água subterrânea, petróleo e problemas geoambientais; Petrofísica e perfilagem geofísica de poços. É sócio da SBGf, da SEG e da EAGE.

Emerson Sidinei Mota dos Santos. Graduado em Geofísica (2005) pela Universidade Federal da Bahia. Professor Substituto do Instituto de Geociências da UFBA e aluno do curso de pós-graduação em Geofísica. Áreas de atuação: Geofísica elétrica em problemas ambientais; métodos geofísicos potenciais. 